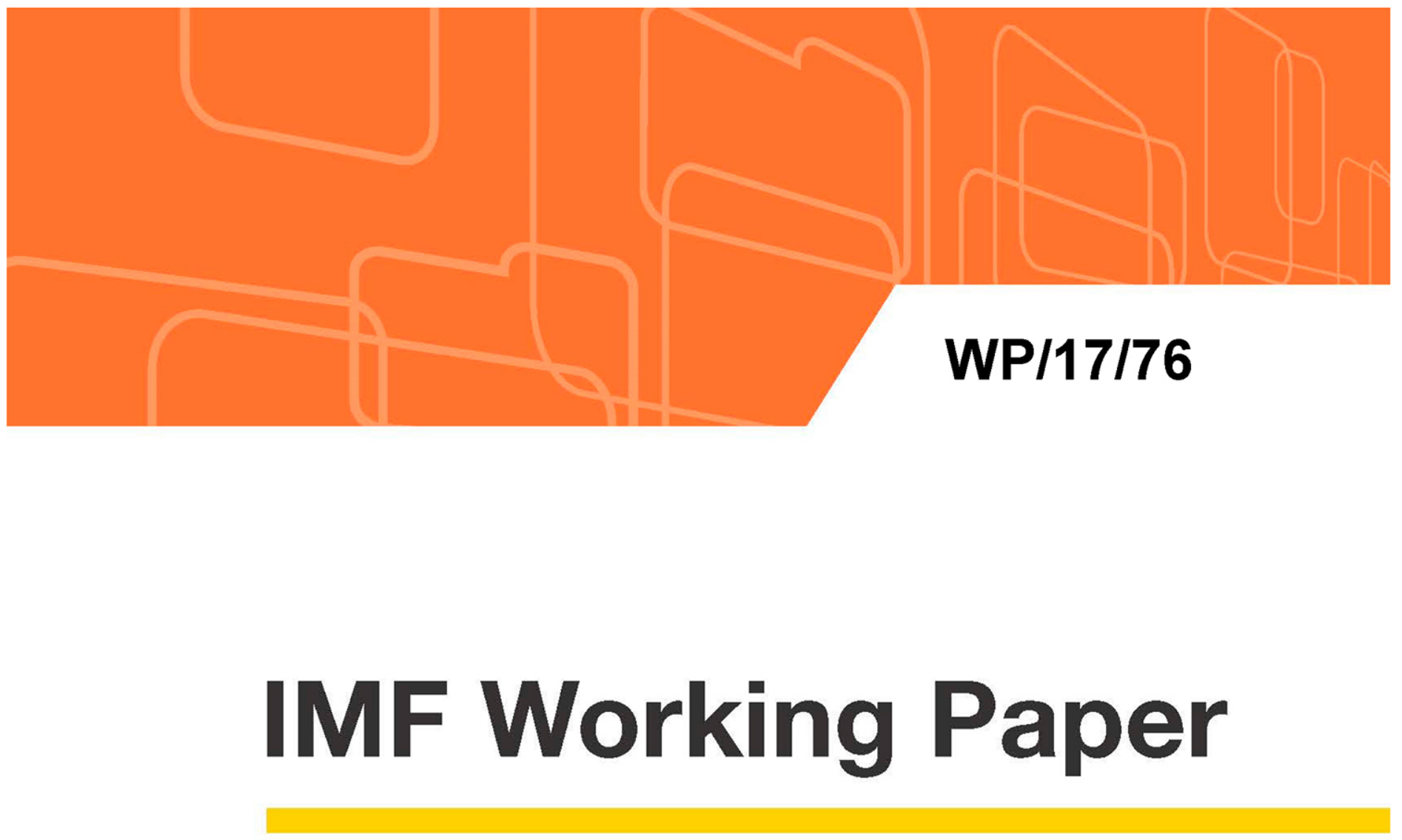

\title{
Inequality Overhang
}

by Francesco Grigoli \& Adrian Robles 


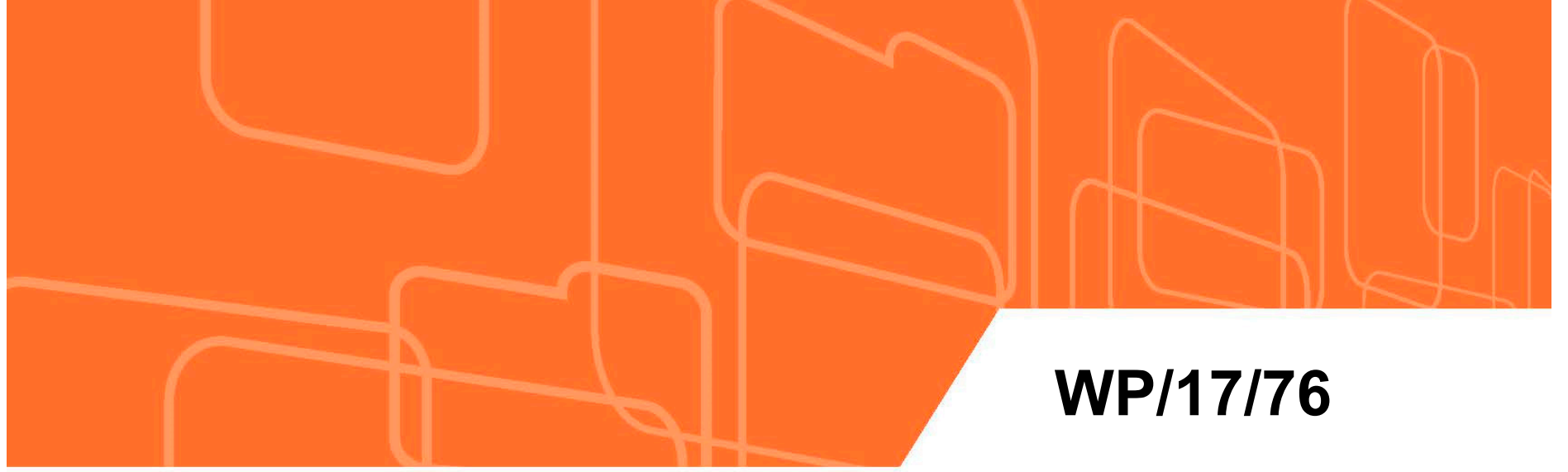

\section{IMF Working Paper}

\section{Inequality Overhang}

by Francesco Grigoli \& Adrian Robles

I N T E R N A T I O N A L M O N E T A R Y F U N D 


\title{
Inequality Overhang*
}

\author{
Francesco Grigoli ${ }^{\dagger} \quad$ Adrian Robles ${ }^{\ddagger}$ \\ Western Hemisphere Department
}

\begin{abstract}
The linearity of the relationship between income inequality and economic development has been long questioned. While theory provides arguments for which the shape of relationship may be positive for low levels of inequality and negative for high ones, most of the empirical literature assumes a linear specification finding conflicting results. Employing an innovative empirical approach robust to endogeneity, we find pervasive evidence of nonlinearities. In particular, similar to the debt overhang literature, we identify an inequality overhang level in that the slope of the relationship between income inequality and economic development switches from positive to negative at a net Gini of about 27 percent. We also find that in an environment characterized by widespread financial inclusion and high income concentration, rising income inequality has a larger negative impact on economic development because banks may curtail credit to customers at the lower end of the income distribution. On the positive side, a sufficiently high female labor participation can act as a shock absorber reducing such negative impact, possibly through a more efficient allocation of resources.
\end{abstract}

Keywords: heterogeneity, Gini, income distribution, income inequality, income levels, growth, nonlinearities.

JEL Codes: E15, O15, O40.

*The views expressed in this Working Paper are those of the authors and do not necessarily represent those of the IMF or IMF policy. Working Papers describe research in progress by the authors and are published to elicit comments and to encourage debate. We thank, without implicating, Madjiyam Bangrim Kibassim, Martin Čihák Alfredo Cuevas, Christian Ebeke, Davide Furceri, Alessandro Giustiniani, Marina Mendes Tavares, Jaques Miniane, Jennifer Moyo, Izabela Karpowicz, Emmanouil Kitsios, Grace Li, Peter Pedroni, Luca Ricci, and the Central Bank of the Federal Republic of Germany for their comments and suggestions.

${ }^{\dagger}$ International Monetary Fund, Western Hemisphere Department, fgrigoli@imf.org.

‡International Monetary Fund, Western Hemisphere Department, arobles@imf.org 


\section{Contents}

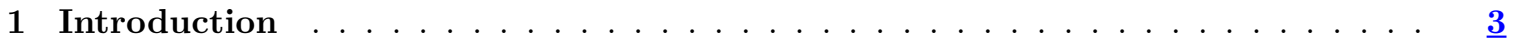

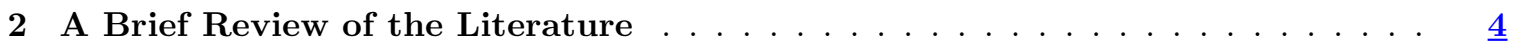

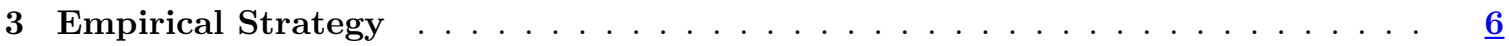

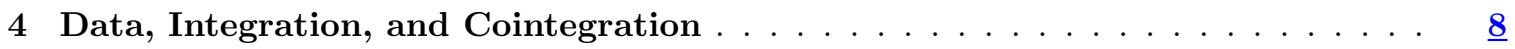

5 Linear or Nonlinear, That Is the Question $\ldots \ldots \ldots \ldots \ldots$

5.1 Inequality Overhang . . . . . . . . . . . . . . . . .

5.2 Financial Inclusion . . . . . . . . . . . . . . . . . . . . . $\underline{15}$

5.3 Female Labor Participation . . . . . . . . . . . . . . . . . . . . . . . $\frac{17}{17}$

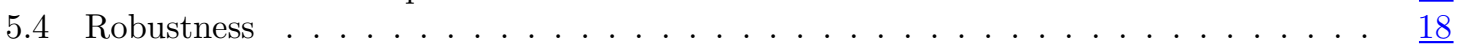

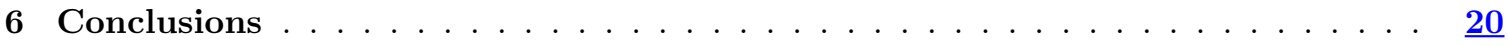

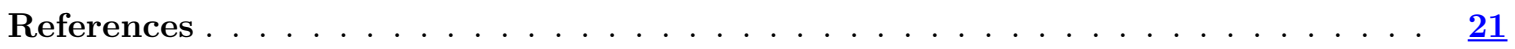

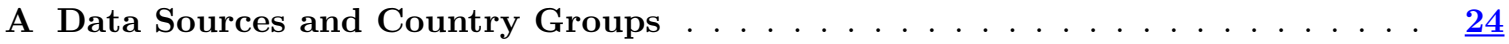

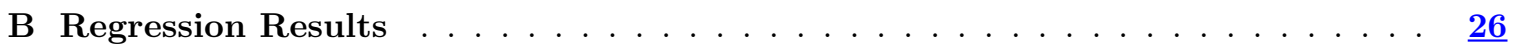

\section{List of Figures}

Page

1 Evolution of the Unconditional Polynomial Relationship Over Time . . . . . . . 11

2 Evolution of the Derivative Over Time . . . . . . . . . . . . . . . $\frac{12}{12}$

3 Average Conditional Relationship and Derivative . . . . . . . . . . . . . $\underline{13}$

4 Variations of the Average Conditional Relationship and Derivative for Different

Levels and Changes of Net Gini . . . . . . . . . . . . . . . . . . . . . . 13

5 Growth Dividend . . . . . . . . . . . . . . . . . . . . . $\underline{14}$

6 Variations of the Average Relationship for Different Levels and Changes of Financial Access . . . . . . . . . . . . . . . . . . . . . . 16

7 Average Derivative for Varying Levels of Net Gini and Financial Access . . . . . . . $\underline{17}$

8 Variations of the Average Relationship for Different Levels and Changes of Female Labor Participation . . . . . . . . . . . . . . . . . $\underline{18}$

9 Average Derivative for Varying Levels of Net Gini and Female Labor Participation . $\underline{19}$

\section{List of Tables}

Page

1 Panel Unit Root Tests . . . . . . . . . . . . . . . . . . . . . . . . $\underline{9}$

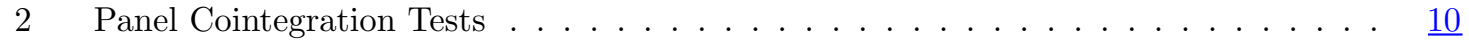

A.1 Data Sources . . . . . . . . . . . . . . . . . . . . . 24

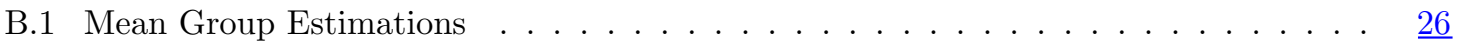




\section{Introduction}

Despite economic theory provides a plethora of arguments in support of a nonlinear relationship between income inequality on economic development, most empirical research has virtually neglected the possibility of nonlinear effects. Kuznets (1955) hypothesized a " 5 percent empirical information and 95 percent speculation" hump-shaped relationship as countries develop from rural economies to industrialized ones. In particular, he argues that in an economy's initial phases of development, capital holders have investment opportunities to increase their wealth, while migration toward urban areas maintains wages relatively low, thereby exacerbating inequality. However, when countries get richer and go through processes of democratization and development of welfare state, inequality declines as the population effectively benefits from a trickle-down effect.

Initial inequality levels also matter, and these are particularly relevant today as many countries experienced a progressive concentration of income over the past few years (Piketty and Saez, 2003; Atkinson et al., 2011; Ostry et al., 2014; Dabla-Norris et al., 2015b; and Grigoli et al., 2016). If the relationship proves nonlinear, there could exist a level (or levels) of inequality after which the direction or the steepness of such relationship changes. As a way to combat the generally accepted result that inequality is harmful for development, some tools have been proposed. Among these, boosting financial inclusion and promoting a more active role of women in the economy captured the attention of policymakers owing to the large room for improvement in many countries. ${ }^{1}$ A more widespread access to financial services and a larger participation of women to the labor force are expected to deliver lower inequality and higher growth (Dabla-Norris et al., 2015a; and Gonzales et al., 2015). However, they could also produce perverse effects through over-leveraging poorer households or generating an over-supply of labor. Thus, it remains unclear if policies aimed at spreading financial access and removing obstacles for women imply trade-offs or rather are winwin policies.

This paper provides a full account of nonlinearities in the relationship between income inequality and economic development, overcoming many of the empirical challenges faced by the other studies. Specifically, the contribution to the existing literature is threefold. First, relying on a recently developed and innovative empirical approach, this paper tests for nonlinearities in the relationship between income inequality and economic development and uncovers how the such nonlinearities evolved over time. Second, it identifies an inequality overhang level, defined as the level at which the impact of income inequality on economic development becomes negative. ${ }^{2}$ Third, it analyzes how the shape of the identified relationship changes for different levels of financial inclusion and female labor participation. We find pervasive evidence of nonlinearities. Also, our findings suggest that the slope of the relationship between inequality and economic development from positive turns negative at a net Gini of about 27 percent, indicating that the inequality overhang occurs at low levels of income inequality. Finally, we find that when financial inclusion is widespread and income is highly concentrated, the negative effects from income inequality become larger, while a context of high female labor participation can effectively contribute to reduce such negative impact and strengthen the positive one.

The rest of the paper is organized as follows. Section 2 reviews the main contributions of the literature to the analysis of nonlinearities in the relationship between income inequality and economic development. Section 3 presents the innovative methodology used for the empirical analysis. Sec-

\footnotetext{
${ }^{1}$ Clearly, there exist other factors that can affect the relationship between income inequality and economic development, including capital account liberalization, fiscal reforms, and labor market reforms. In this paper, we limit our analysis to financial inclusion and female labor participation.

${ }^{2}$ We borrow the terminology from the debt overhang literature, which, in a nutshell, defines the debt overhang as a condition for which debt is large enough to have a negative impact on economic growth (Krugman, 1988).
} 
tion 4 discusses data and their properties. Section 5 presents the results. Section 6 concludes.

\section{A Brief Review of the Literature}

Beyond the hypothesis advanced by Kuznets (1955), other contributions provided theoretical arguments suggesting that the stage of economic development determines the shape of the relationship between inequality and growth. Galor (2000) and Galor and Moav (2004) argue that poorer countries are generally characterized by scarce physical capital with high returns, while in richer countries human capital becomes the prominent driver of growth. Hence, inequality is positively correlated with growth in poorer countries to the extent that it contributes to channel resources to individuals with higher marginal propensity to save, spurring investment. Inequality, however, adversely affects growth in more developed economies as it reduces the chance for poorer individuals to access education.

Initial inequality levels are also relevant. Benhabib (2003) proposes a theoretical model for which increases in inequality in a context of low levels of inequality can provide incentives to be more productive hence spurring growth, while increases from higher levels of inequality could lead to rent-seeking behaviors thereby depressing growth. Also, when inequality is low, it is unlikely that more inequality leads to social unrest. Conversely, when inequality is already high, any increase in inequality is more plausible to reduce social consensus and trigger unrest, that ultimately dampens investment and growth (Alesina and Rodrik, 1991; Alesina and Perotti, 1996; Benabou, 1996; and Ostry and Berg, 2011). Furthermore, since low levels of inequality are preferable, any shock raising the inequality level from an initially low level is unlikely to generate discontent and affect the likelihood of passing pro-growth reforms. However, when inequality is high, consensus is often lacking and reforms become less likely (Kim and Pirttila, 2003).

At the same time, other factors are likely to play a role in shaping the relationship between inequality and levels of income. Financial development, for example, is generally thought to boost economic performance by improving the allocative efficiency of capital and mitigating the effects of information and transaction costs. This, in turn, should increase saving and investment, spurring technological innovation, and raising long-run growth rates (Pagano, 1993; and Levine, 1997).

Some recent studies analyze whether there is a point beyond which the benefits of financial development disappear and actually become costs (Masten et al., 2008; Cecchetti and Kharroubi, 2012; Arcand et al., 2015; Sahay et al., 2015; and Al Masri and Pedroni, 2016). Financial development is likely to have contemporaneous effects on income inequality (Greenwood and Jovanovic, 1990). As discussed in Dabla-Norris et al. (2015a), greater financial inclusion or access generally brings financial services to the poorer, often credit-constrained, portion of the population. ${ }^{3}$ Rajan (2011) argues that raising inequality pushes politicians to foster easy credit to help equalize consumption, and suggests that the combination of inequality and leverage can create the premises for crises. In other words, if income gets more concentrated in a context of widespread access to financial services, credit to those that became poorer may be curtailed due to their diminished ability to repay. This, in turn, may lead to a reduction in consumption, thereby exacerbating the impact of income inequality on economic development.

Gender-based inequality is also at the core of less equitable societies and unsatisfactory develop-

\footnotetext{
${ }^{3}$ Dabla-Norris et al. (2015a) note that typical regression analysis may not be suitable to understand the impact of financial deepening as they assumptions of linearity and stationarity seldom hold. Also, they note that regression analysis cannot provide much information on how financial deepening transmits to the economy and what feedback loops exist among finance, growth, and inequality. As a result, policy analysis is often difficult to carry out.
} 
ment performances. There is a lively strand of research arguing for a strict association between gender inequality and income inequality (Gonzales et al., 2015) and a positive effect on development from a reduction of gender inequality (Duflo, 2012). Gender gaps in labor participation result in inequality of earnings, also because women that are not part of the labor force are often employed in the informal sector (characterized by lower wages). Further, raising female labor participation can spur long-term income levels through more expenditure on school enrollment owing to women's higher propensity to invest in their children's education (Thomas, 1990; Miller, 2008). Also, removing obstacles that prevent women from participating in the economy can promote a more efficient resource allocation and higher total factor productivity by effectively enlarging the pool of talented individuals (Teignier and Cuberes, 2014). Simultaneous effects are also possible. For example, if income gets more concentrated in a context of high female labor participation, the more productive labor force may contrast the negative effect of income inequality on economic development.

The empirical research investigating nonlinearities between inequality and growth is scarce. Banerjee and Duflo (2003), similar to Chen (2003), suggest that growth is an inverted U-shape function of income inequality, and that the inconclusiveness of previous studies regarding the impact of the former on the latter is related to the imposition of a linear structure. This view is consistent with the results of Barro (2000), that finds that the impact of inequality on growth might be dependent on the level of development, using a three-stage least squares estimator and splitting the sample into poorer and richer countries. Following this idea, De Dominicis et al. (2006) opt to limit the analysis to a more homogeneous set of countries or to regions within a country. Grigoli et al. (2016) employ a heterogeneous panel technique, in fact controlling for cross-country differences in income, and note that cross-country dispersion of the effect of inequality on growth is large, and that the effect is negative and significant only in emerging markets (EM).

A few recent studies explicitly study nonlinearities. Lin et al. (2009) use threshold regressions on cross-sectional data with instrumental variables and find evidence that an increase in inequality slows growth in low-income countries, but accelerates it in high-income ones. Kolev and Niehues (2016) employ ordinary least squares (OLS) and generalized method of moments (GMM) estimators on panel data. Their results suggest that the negative effect of income inequality on growth is significant for less-developed countries and that the negative effect diminishes and becomes positive for high income level countries. Conditioning on the level of inequality, they find that the effect is negative for countries with high levels of inequality and for low levels of initial inequality. Cho et al. (2014) utilize a panel smooth transition regression model with panel data conditioning on initial levels of income inequality. Their findings suggest that the effect of inequality on growth turns from positive to negative when the Gini is higher than 24.5 percent. Using GMM panel estimations, Ostry et al. (2014) do not find strong evidence that the negative impact of inequality on growth depends on the initial level of inequality.

The literature of nonlinearities with respect to other variables remains limited. Fallah and Partridge (2007) argue that the relationship between inequality and growth is positive for a higher degree of urbanization, while it is negative when urbanization is low. Bjørnskov (2008) finds evidence suggesting that under left-wing administrations the relationship is negative, while it becomes positive for right-wing administrations. 


\section{$3 \quad$ Empirical Strategy}

The investigation of nonlinearities in the panel data literature on the effects of income inequality on economic development is mostly confined to quadratic specifications. However, relationships may be better described by higher-order polynomials. Also, classical OLS panel regressions remain subject to endogeneity owing to a series of issues, such as reverse causality, simultaneity, omitted variables, measurement error, cross-sectional dependence, and heterogeneous dynamics. GMM estimations are often used to bypass the endogeneity issues. Nonetheless, as pointed out by Kraay (2015), the GMM estimator is not suitable for growth regressions as internal instruments are weak and results in biased inference. ${ }^{4}$

Departing from the literature, we employ here the innovative approach developed by Al Masri and Pedroni (2016), which provides robustness to any form of endogeneity. We start from the following classical OLS panel regression:

$$
y_{i, t}=\alpha_{i}+\sum_{j=0}^{P} \beta_{j} X_{i, t}^{j}+u_{i, t}
$$

where $y_{i, t}$ is real per capita GDP for country $i$ at time $t, X_{i, t}$ is the net Gini coefficient, $\alpha$ and $\beta$ are the relative coefficients, and $u_{i, t}$ is the error term assumed to be independent and identically distributed. Al Masri and Pedroni (ibid.) argue that estimating this regression would return inconsistent estimates owing to the econometric issues mentioned above. Thus, we proceed, as in their paper, by breaking down equation (1) in two steps. The first step involves static linear time series regressions:

$$
y_{i, t}=\alpha_{i}+\beta_{i} X_{i, t}+u_{i, t}
$$

Since these are regressions between cointegrated unit root variables, the property of superconsistency ensures that the slope parameters are robust to endogeneity caused by reverse causality, omitted dynamics, and omitted stationary variables, among others. Al Masri and Pedroni (ibid.) note that even if the variables are not cointegrated, the second step of the methodology employed here preserves this robustness as the rate of convergence to the true values of the parameters is a function of both $N$ and $T .{ }^{5}$

In the second step, we run a series of cross-section regressions (i.e., one for every time period) of the estimated time-invariant country-specific coefficient $\hat{\beta}_{i}$ :

$$
\widehat{\beta}_{i}=\sum_{j=0}^{P} C_{j, s} X_{i}(s)^{j}+E_{s} R_{i}(s)+v_{i}
$$

where $X_{i}(s)_{i}^{j}$ is used as a notation for $X_{i, s}, \sum_{j=0}^{P} C_{j, s} X_{i}(s)^{j}$ is a polynomial matrix of order $P$, and $C_{j, s}$ is the corresponding polynomial matrix of coefficients. ${ }^{6} E_{s}$ and $R_{i}(s)$ are matrices of control variables (initial level of income, trade openness, terms of trade, investment in percent of GDP, and population growth) and related coefficients. ${ }^{7}$ We select the order of the polynomial

\footnotetext{
${ }^{4}$ Kraay (2015) notes that once he corrects inference for weak instruments, he finds no evidence of a positive or negative effect of income inequality on growth.

${ }^{5}$ While cointegration ensures consistency of estimation, it does not dictate the direction of causality. Thus, without a priori restrictions, cointegration is equivalent to the instrumental variable approach in that it provides robustness asymptotically.

${ }^{6}$ This notation is used to avoid confusion regarding the estimation of cross-section regressions. In particular, $X_{i}(s)_{i}^{j}$ is used to indicate values of the independent variables at a specific point in time $s$ rather than over time $t=1, \ldots, T$.

${ }^{7}$ Since data proxying human capital like years of schooling and education attainment present many missing observations, we only include them in robustness tests.
} 
with a general-to-specific (GTS) procedure, i.e. starting with a polynomial of order three and dropping the highest insignificant term, for every cross-section estimation. For most years, the cross-section estimation delivers a polynomial of order two describing a quadratic relationship. In same rare cases, however, a polynomial of order three (corresponding to a cubic relationship) is selected.

The particular nature of the cross-section regressions involves the use of partial sums of unit root processes, which ensures that superconsistency is retained even without cointegration. Thus, unconditional or conditional estimates converge to the true value at a rate that grows very quickly in $N$, avoiding nonsensical results. Also, by estimating cross-section regressions, we address the issue of cross-sectional dependence, which in a panel context would have had to be tackled by extracting unknown common components.

Armed with the fitted values from equation (2) and (3), we can now calculate the polynomial of order $P+1$ as:

$$
y_{i, t}=\widehat{\alpha_{i}}+\sum_{j=0}^{P} \widehat{C_{j, s}} X_{i}(s)^{j} X_{i}+\widehat{E_{s}} R_{i}(s) X_{i}
$$

This allows to trace out the polynomial function for every time period $s$ and observe how the relationship between income inequality and economic development evolves over time. Also, we can retrieve the average relationship. First, we compute the mean group coefficients as $\widehat{\widehat{c_{j}}}=T^{-1} \sum_{s=1}^{T} \widehat{c_{j, s}}$, and the associated $t$-statistic as $\overline{t_{j}}=T^{-1 / 2} \sum_{s=1}^{T} t_{j, s}$ to check the significance of all the polynomial terms with a GTS procedure. Then, we calculate the average relationship as:

$$
y_{i}=\widehat{\alpha_{i}}+\sum_{j=0}^{P} \overline{\widehat{C_{j}}} \overline{X_{i}^{j}} X_{i}+\overline{\widehat{E}} \overline{R_{i}} X_{i}
$$

which, in our case of a quadratic relationship in equation (3), would translate into the following cubic equation:

$$
y_{i, t}=\widehat{c_{o, s}} x_{i, t}+\widehat{c_{1, s}} x_{i}(s) x_{i, t}+\widehat{c_{2, s}} x_{i}(s)^{2} x_{i, t}+\widehat{e_{s}} r_{i}(s) x_{i, t}
$$

To look into the impact of the net Gini on real per capita GDP growth, we take the first derivative of equation (5) with respect to $X_{i}$ :

$$
\frac{\delta y_{i}}{\delta X_{i}}=\sum_{j=0}^{P} \overline{j \widehat{C_{j-1}}} \overline{X_{i}^{j-1}}+\overline{\widehat{E}} \overline{R_{i}}
$$

that in our case of a cubic relationship can be written as the following quadratic function:

$$
\frac{\delta y_{i}}{\delta x_{i}}=\overline{\hat{c}_{o}}+\widehat{e_{s}} r_{i}(s)+2 \widehat{c_{1}} \overline{x_{i}}+3 \widehat{c_{2}}{\overline{x_{i}}}^{2}
$$

and plot it against $x_{i}$. This would allow investigating the level(s) of inequality at which the impact of a change in inequality on income growth is negative, zero, or positive, and therefore identifying the inequality overhang as the level of income inequality after which such effect goes from positive to negative.

Finally, we explore some of the interaction effects of interest. Thus, equation (3) becomes:

$$
\widehat{\beta}_{i}=\sum_{j=0}^{P} \widetilde{C_{j, s}} X_{i}(s)^{j}+E_{s} R_{i}(s)+\sum_{k=1}^{K} \sum_{j=0}^{P} D_{k, j} X_{i}(s)^{j} Z_{k, i}+v_{i}
$$


where $D_{k, j}$ is a coefficient matrix for the interaction terms between the polynomial in net Gini $X_{i, t}$ and a cross-sectional variable of choice $Z_{i}$ (alternatively, financial access and female labor participation). Hence, the polynomial in equation (6) can be rewritten as:

$$
\begin{aligned}
y_{i, t}= & \widehat{\alpha_{i}}+\widehat{c_{o, s}} x_{i, t}+2 \widehat{c_{1, s}} x_{i}(s) x_{i, t}+3 \widehat{3 c_{2, s}} x_{i}(s)^{2} x_{i, t}+\widehat{e_{s}} r_{i}(s) x_{i, t}+ \\
& \widehat{d_{o, s}} z_{i} x_{i, t}+2 \widehat{d_{1, s}} z_{i} x_{i}(s) x_{i, t}+3 \widehat{d_{2, s}} z_{i} x_{i}(s)^{2} x_{i, t}
\end{aligned}
$$

\section{Data, Integration, and Cointegration}

The dataset employed for this analysis builds on the Standardized World Income Inequality Database (SWIID) 5.1 for net Gini (where net refers to its measurement after taxes and transfers) and on the Penn World Tables (PWT) 9.0 for the real income variable and population to construct the per capita version of real income. ${ }^{8,9}$ As we are interested in analyzing the relationship between post-redistribution income and economic development, we prefer net Gini over market Gini. ${ }^{10}$

As in Grigoli et al. (2016), we run some data exclusion criteria to end up with non-stationary continuous time series observations for net Gini. ${ }^{11}$ Specifically, criterion one consists of excluding all non-continuous time series, remaining with the longest run for every country for which data is available. The second criterion excludes all observations for a specific country if the longest run obtained by running the first criterion is shorter than 20 observations, consistent with the remarkable small sample properties of the methodology employed. ${ }^{12}$ The third and last criterion consists of dropping all countries for which the net Gini is stationary to ensure unbiased estimates in the times series regressions. ${ }^{13}$ Thus, the remaining dataset includes 77 countries spanning a minimum of 20 years, for a total of 1,597 data points.

As mentioned in Section 3, the methodology used in this paper requires unit roots for the variables entering the time series regressions. In Table 1, we report the panel unit root test results for net Gini and (the log of) real per capita GDP including the intercept only and the intercept and the trend. The results of the tests by Levin et al. (2002) (LLC thereafter), Im et al. (2003) (IPS

\footnotetext{
${ }^{8}$ The SWIID database is built by using several categories of welfare definitions and equivalence scales, constructing time- and country-varying ratios of indexes available in different categories, and generating the missing ratios using the least uncertain predictions of a set of regression models. Ratios for each category are finally combined into a final estimate by taking into account the estimate with the smallest uncertainty. See Jenkins (2015) and Solt (2016) for an in-depth discussion about data construction and reliability of the SWIID estimates in crosscountry studies.

${ }^{9}$ See Appendix A for the list of variables used in this paper and their sources.

${ }^{10}$ While the net Gini excludes redistributive interventions, it still includes a wide range of non-redistributive policies that contribute to shape income distribution (Iversen and Stephens, 2008; and Morgan and Kelly, 2013).

${ }^{11}$ While net Gini is bounded between zero and one, it can still present non-stationary properties over the sample period (i.e., locally non-stationary), bearing implications for the properties of the estimators constructed from this sample (see Cavaliere, 2005, and Granger, 2010 for a discussion about the possible coexistence of the nonstationarity concept with the constraints of bounded or limited series, and Pedroni, 2007 for an application to investment shares). As a robustness test, we apply the logistic transformation $y_{i, t}=\ln \left[n_{i, t} /\left(1-n_{i, t}\right)\right]$, where $n_{i, t}$ is the net Gini. Applying such transformation does not affect any of the results presented in this paper.

${ }^{12} \mathrm{Al}$ Masri and Pedroni (2016) present the robustness features of the methodology using $N=30$ and $T=30$. Reducing the sample to the countries with a net Gini series of such length would leave us with only $N=21$ after applying all data exclusion criteria, biasing the sample towards advanced economies. Thus, we set the threshold to $T=20$. As shown in Al Masri and Pedroni (ibid.), the biases induced by endogeneity and cross-sectional dependence remain small even with such series length. Further, we rely on a much larger $N$ than the one used by the authors.

${ }^{13}$ The application of the third criterion implies the loss of 9 countries (Denmark, Estonia, Georgia, Netherlands, Romenia, Senegal, Slovenia, Spain, and Uruguay) or 11 percent of the dataset obtained after applying the second criterion.
} 
Table 1: Panel Unit Root Tests

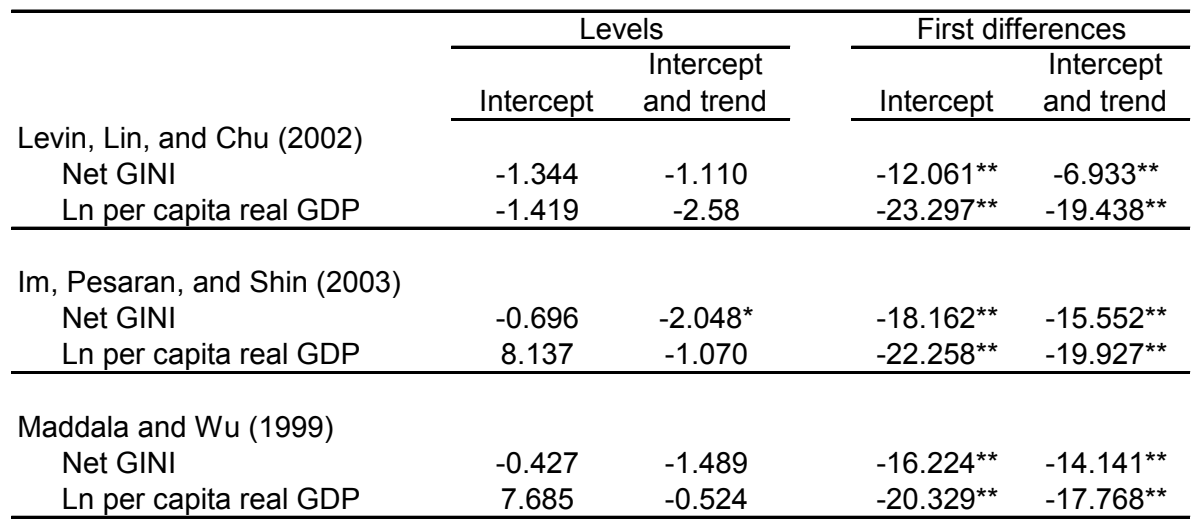

Source: Authors' calculations.

Notes: The null hypothesis of the panel unit root tests is that all panels contain a unit root. Fixed effects are always included. The Schwartz Information Criterion is used to select the optimal lag length. ${ }^{* *}$ and ${ }^{*}$ next to a number indicate statistical significance at 1 and 5 percent, respectively.

thereafter), and Maddala and Wu (1999) (MW thereafter) suggest that both variables are integrated of order one. ${ }^{14}$

While cointegration is not required by the methodology employed in this paper, it remains desirable. Hence, we report the results from the panel cointegration tests by Kao (1999) and Pedroni $(1999,2004)$ in Table $2 .{ }^{15}$ The results confirm that net Gini and (the log of) real per capita GDP are cointegrated, indicating the existence of a long-run relationship between the variables.

\section{Linear or Nonlinear, That Is the Question}

\section{$5.1 \quad$ Inequality Overhang}

We start by analyzing how the unconditional relationship between income inequality and real per capita GDP evolves over time. ${ }^{16}$ As mentioned in Section 3, we run a GTS procedure to allow the polynomial to take the shape that best describes the data. Such procedure confirms the existence of nonlinearities as it returns a quadratic relationship for most of the years and a cubic relationship in a very few years. Figure 1 presents the polynomial relationship every five years during 1975-2010, differentiating income groups by color. ${ }^{17}$ At the beginning of the sample period, the number of observations is greatly reduced, as only a few advanced economies (AE) and EM

\footnotetext{
${ }^{14}$ In a nutshell, the differences across the panel unit tests are that LLC treats the parameter of interest as common across countries and focuses on the within-country dimension, IPS treats the parameter of interest as varying across countries and focuses on the between-country dimension, and MW treats all the parameters as potentially varying across countries and tests by pooling significance values across members of the panels.

${ }^{15}$ Kao (1999) treats all parameters except fixed effects as homogeneous, thereby assuming homogenous dynamics. Pedroni $(1999,2004)$ treat all parameters as heterogeneous across countries and include within- and betweencountry dimension tests, both parametric and non-parametric.

${ }^{16}$ The unconditional results are asymptotically robust to the endogeneity caused by omitted variables owing to the superconsistency properties of the estimation method.

${ }^{17}$ While the relationship can be plotted for each year, we report it only every five years to ease visualization. With the same aim, we set the fixed effect $\alpha_{i}$ to zero in equation (6).
} 
Table 2: Panel Cointegration Tests

\begin{tabular}{lcc}
\hline & & \\
Kao (1999) & Intercept & $\begin{array}{c}\text { Intercept } \\
\text { and trend }\end{array}$ \\
\cline { 2 - 3 } ADF & & \\
\hline & $-3.867^{* *}$ & \\
Pedroni $(1999,2004)$ & & \\
Panel $v$-Statistic & 0.038 & $2.655^{* *}$ \\
Panel $\rho$-Statistic & $-0.213^{*}$ & 1.823 \\
Panel $t$-Statistic (non-parametric) & $-2.821^{* *}$ & $-0.628^{*}$ \\
Panel $t$-Statistic (parametric) & $-1.980^{* *}$ & $-4.067^{* *}$ \\
Group $\rho$-Statistic & 1.561 & 4.595 \\
Group $t$-Statistic (non-parametric) & $-3.324^{* *}$ & 1.246 \\
Group $t$-Statistic (parametric) & $-6.660^{* *}$ & $-4.981^{* *}$ \\
\hline
\end{tabular}

Source: Authors' calculations.

Notes: The null hypothesis of the panel cointegration tests is that there is no cointegration between net Gini and $\ln$ real per capita GDP. For Pedroni $(1999,2004)$, we present the versions of the statistics that are not weighted by the member specific long-run conditional variances. The Schwartz Information Criterion is used to select the optimal lag length. ** and * next to a number indicate statistical significance at 1 and 5 percent, respectively.

have series going back to those years. ${ }^{18}$ Starting in 1990, at least 95 percent of the sample of 77 countries is represented, with a more even composition across AE, EM, and low-income developing countries (LIDC). Hence we focus on this temporal subset.

The panels in Figure 1 reveal the existence of different phases in the relationship between inequality and real per capita GDP. Before the 2000s, the relationship is positive for low levels of income inequality (up to a net Gini of less than 30 percent), generally experienced by AE and a few EM. For higher levels of income inequality (net Gini higher than about 30) experienced by only a few $\mathrm{AE}$ and mostly EM and LIDC, the relationship becomes negative. For very high levels of income inequality typical of LIDC and EM (net Gini higher than about 50 percent), the relationship flattens again and becomes positive in 1990. Interestingly, these positive phases progressively flatten and disappear over time. In fact, starting in 2000, the relationship is strictly negative for all levels of inequality, in part because less countries present low levels of income inequality. However, it still features an increasingly negative slope as the level of income inequality rises.

Our interest falls on the impact of changes in net Gini on real GDP growth for different levels of net Gini. Figure 2 presents the evolution over time of the derivative of real per capita GDP with respect to net Gini calculated as in equation (8). Depending on the slope of the polynomial relationship, the shape of the derivative can take either positive or negative values. Unsurprisingly, the derivative is described by a quadratic function until 1990 (when the polynomial relationship is described by a cubic function and the sample is missing many LIDC) and a linear function thereafter (when the polynomial relationship is a quadratic function, the sample is more evenly balanced, and many AE started to experience higher levels of inequality). The results confirm that the impact of income inequality on growth is positive for low levels of net Gini until 1995, and then becomes negative for all countries in the sample. ${ }^{19}$ Starting in 1995, the derivative is depicted by a negatively sloped linear function, suggesting that the polynomial relationship is nonlinear and characterized by an increasingly more negative impact as income inequality raises.

\footnotetext{
${ }^{18}$ See Appendix A for details regarding income groups.

${ }^{19}$ Only in 1990 the polynomial relationship shows positive growth effects from changes in inequality at very high levels of income inequality.
} 
Figure 1: Evolution of the Unconditional Polynomial Relationship Over Time
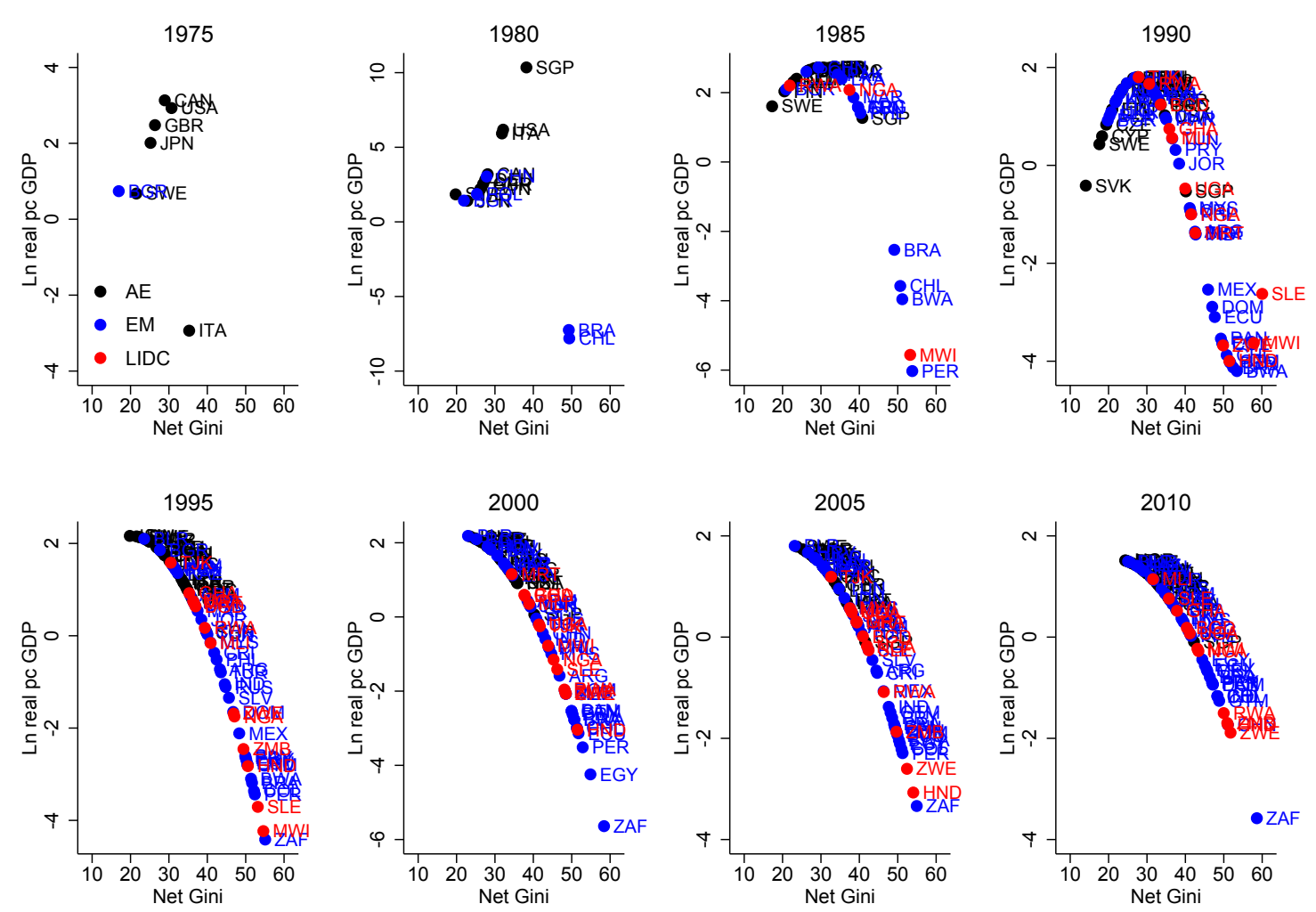

Source: Authors' calculations.

Since year-specific estimations can be noisy and we are interested in the conditional effect of income inequality on real per capita GDP, we present the average polynomial relationship in Figure 3 over 1990-2010 allowing for control variables. ${ }^{20}$ The average relationship is best described by the cubic function depicted in the left panel. This is steep and negative for most of net Gini values, but flattens out and becomes mildly positive for low levels of inequality. This shape is not inconsistent with the results shown in Figure 1 for two reasons. First, we are now controlling for other variables, and second, even the unconditional relationship is best explained by a cubic function during 1990-94 (or one fourth of the time span), thereby affecting the average.

The right panel of Figure 3 shows the correspondent average derivative, characterized by a quadratic function with the familiar concave shape observed in some panels of Figure 2. Calculating the solutions of the quadratic equation suggests that the inequality overhang occurs at a level of net Gini of about 27 percent. ${ }^{21}$ In other words, in a context of low income inequality levels, an increase in income inequality has a positive effect on growth. However, for inequality levels higher than the identified threshold, any increase in income inequality has an inexorable negative effect on growth, which strengthens as income inequality rises.

As discussed in Section 3, one of the advantages of the use of data-driven polynomials in levels is the ability to retrieve information with respect to the relationship between growth rates or different combinations of levels and growth rates. In other words, without re-estimating, we can rely on

\footnotetext{
${ }^{20}$ See Appendix B for the results of the mean group estimations.

${ }^{21}$ The other root of the quadratic equation is negative and does not have an economic meaning.
} 
Figure 2: Evolution of the Derivative Over Time
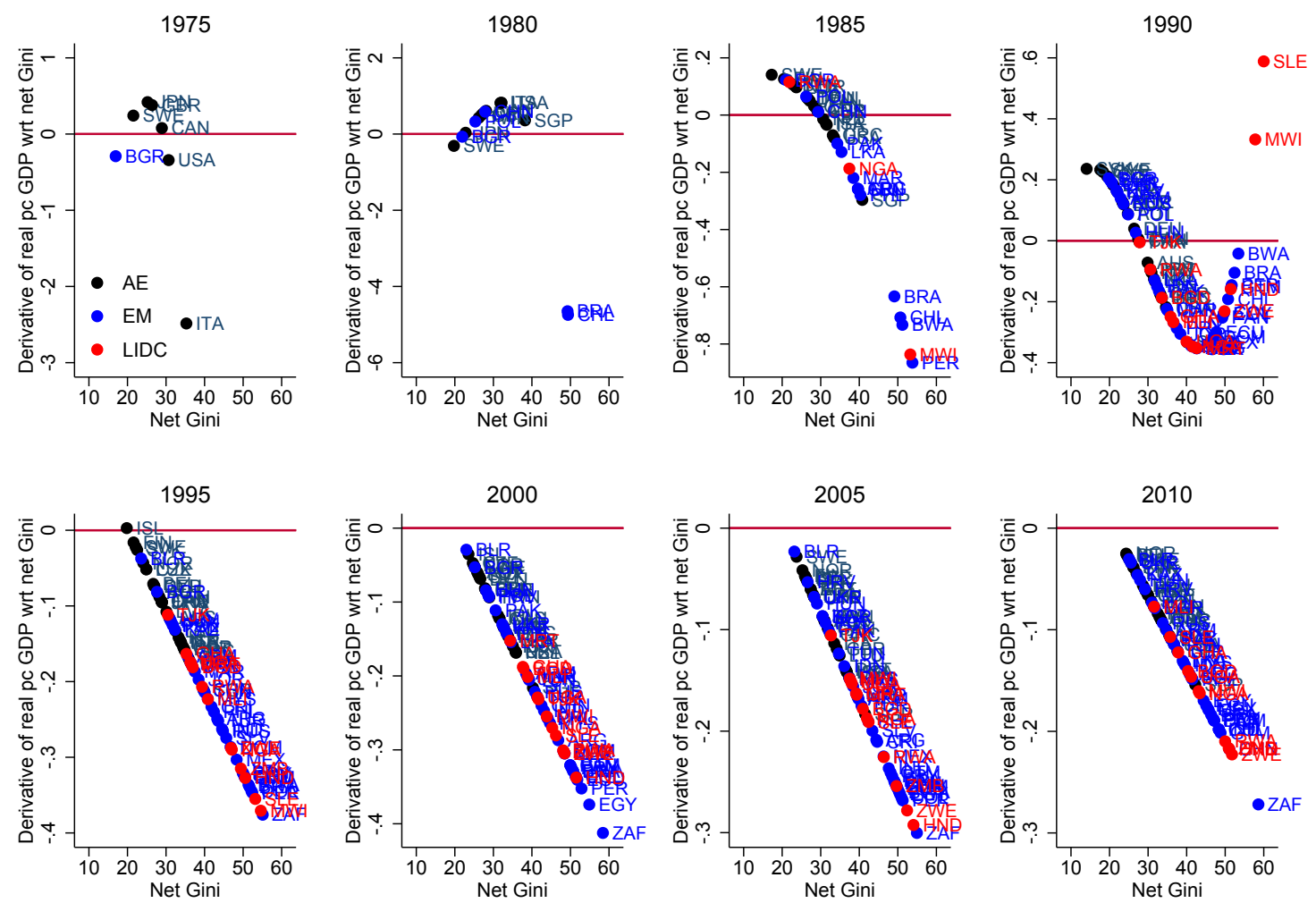

Source: Authors' calculations.

equation (8) as an alternative way to depict the relationships among growth rates and levels. The left panel of Figure 4 plots the relationship between real per capita GDP growth and net Gini. The relationship described by the black dots is the one that assumes changes in net Gini equal to one, therefore numerically identical to the one plotted in the right panel of figure 3. Conditioning on different steady state changes in income inequality (blue and red markers), we show that the relationship turns out steeper for larger steady state changes in net Gini. The right panel of Figure 4 shows the relationship between the growth rate of real per capita GDP and changes in net Gini (black dots), this time conditioning on different levels of net Gini (blue and red markers). Once again, it is clear that the relationship is not constant, but varies over different levels of net Gini. In particular, besides the familiar negative relationship for the average net Gini levels (about 37 percent), there exists a positive relationship when we halve the average level of net Gini, and a steeper negative relationship when we increase it.

As a last step, we calculate what would be the growth dividend from reducing income inequality. Reducing net Gini to the overhang level would be unrealistic for many countries in the sample. For example, Argentina displays an average net Gini of 44 percent over 1990-2010, with the coefficient never below 40 percent. A reduction from 44 percent to 27 percent would be dramatic. Thus, we run two experiments. The first assumes that every country reduces inequality by the sample average of the change in net Gini, i.e. 0.13 percentage points (pp). The second experiment assumes a more ambitious reduction in net Gini by one pp. 
Figure 3: Average Conditional Relationship and Derivative
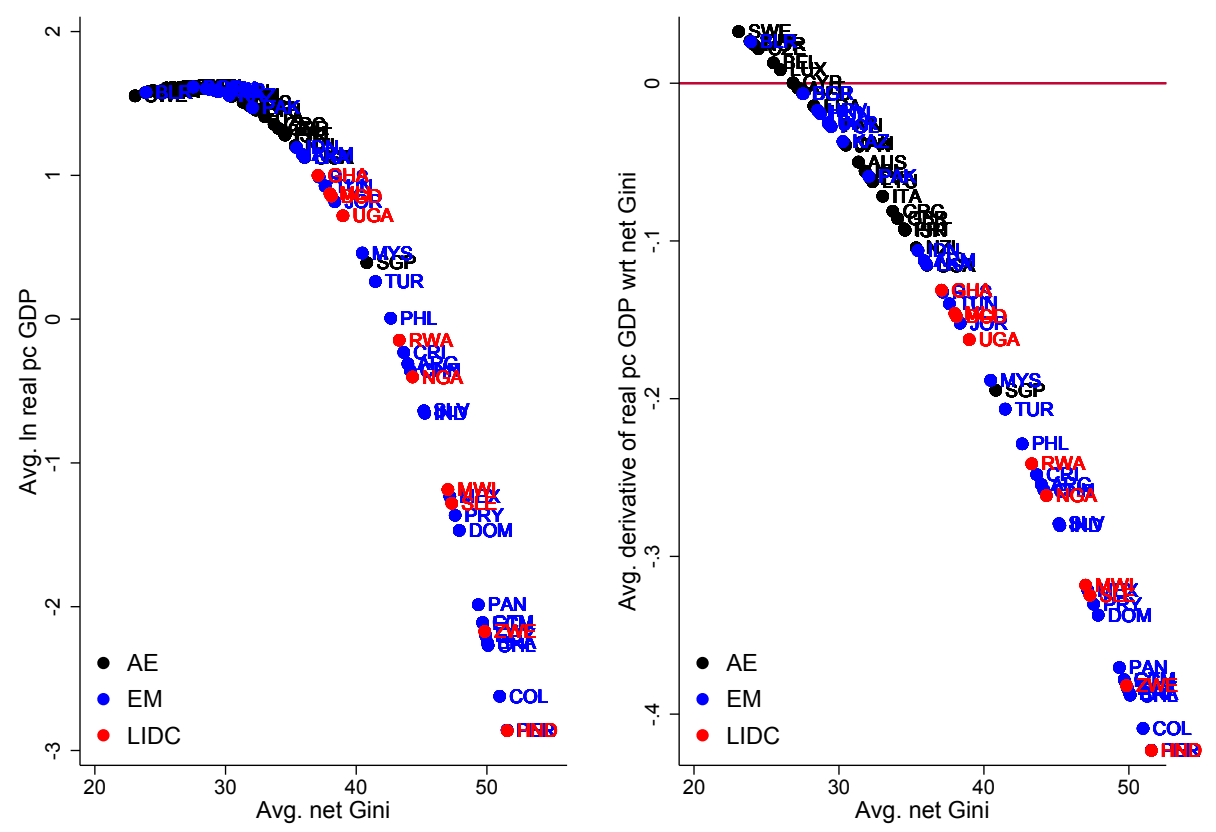

Source: Authors' calculations.

Figure 4: Variations of the Average Conditional Relationship and Derivative for Different Levels and Changes of Net Gini
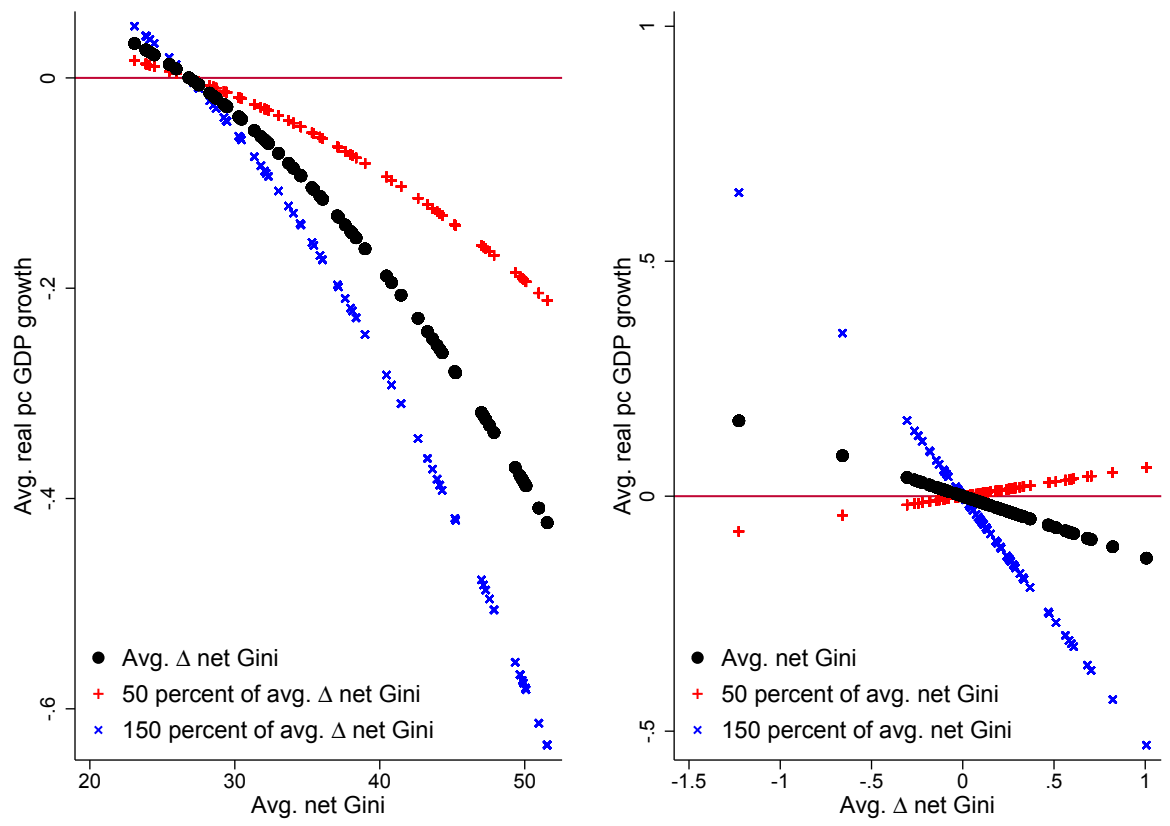

Source: Authors' calculations. 
Figure 5: Growth Dividend

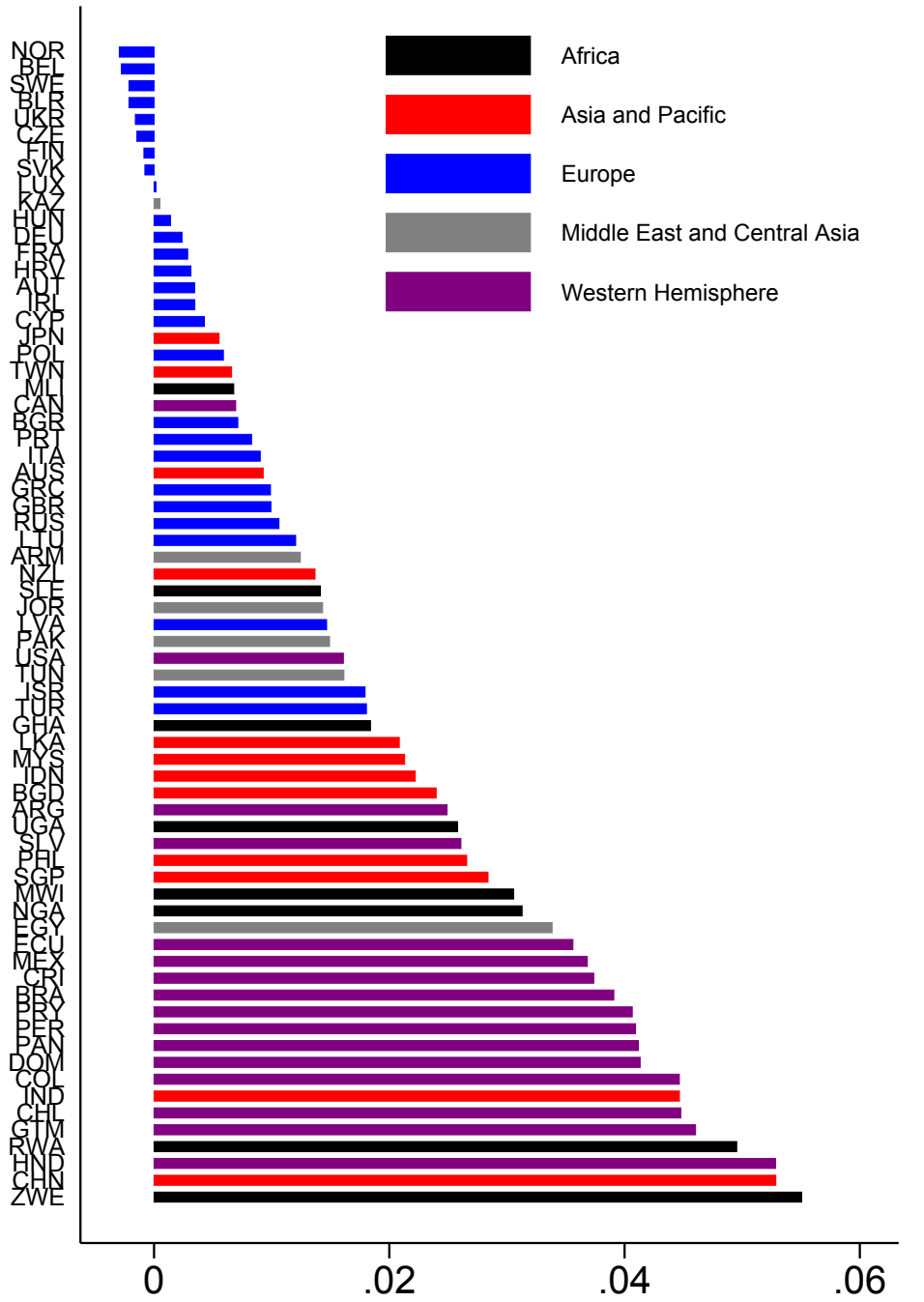

Change in real pc GDP growth associated with an avg. reduction in net Gini Source: Authors' calculations.

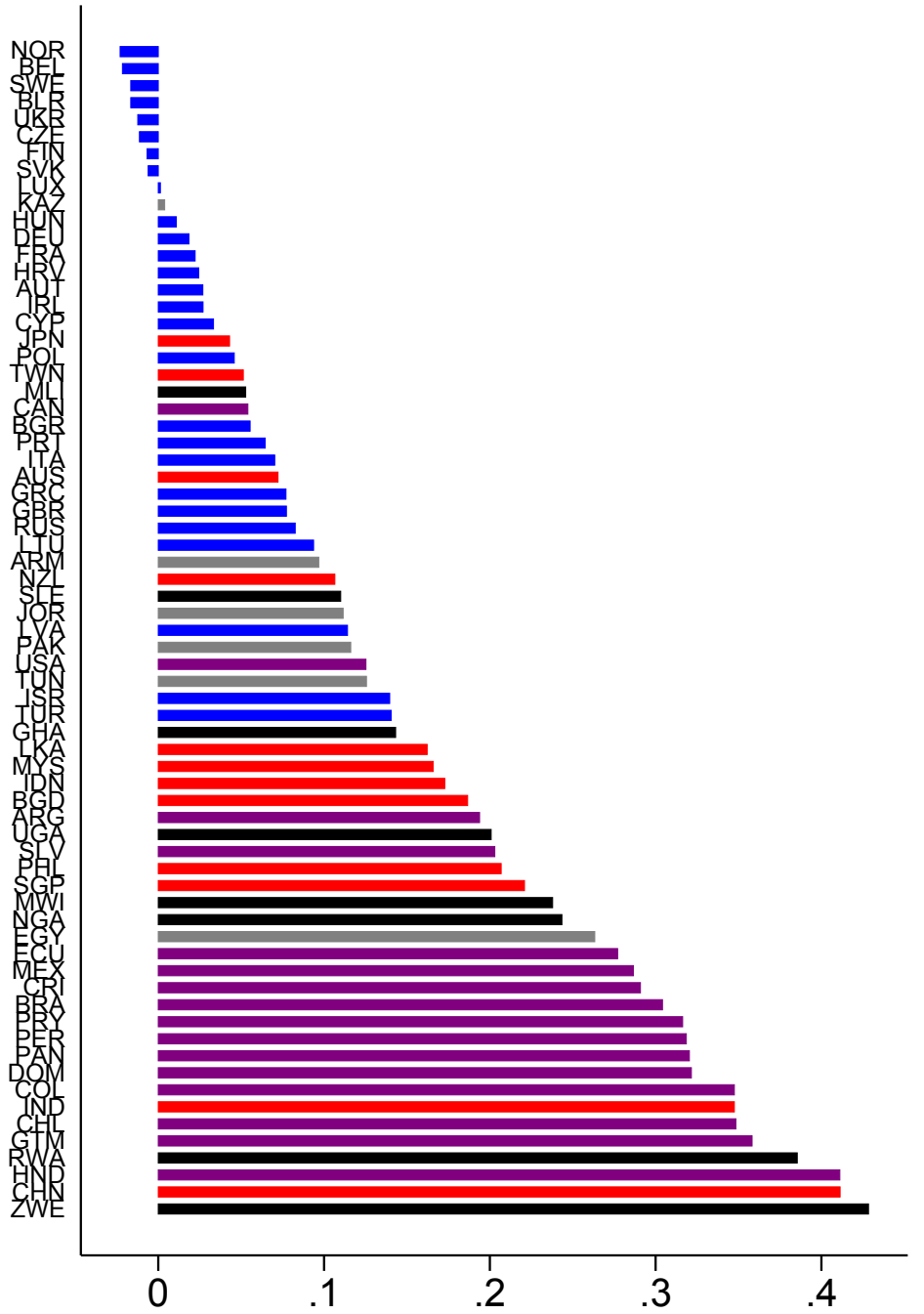

Change in real pc GDP growth associated with a one pp reduction in net Gini 
In Figure 5, we plot the potential gains in terms of real per capita GDP growth for the two experiments. ${ }^{22}$ It should be noted that the results vary according to the initial level of income inequality, in line with the uncovered nonlinearities. In fact, real per capita GDP in countries with a higher level of income inequality is more sensitive to changes in income inequality. The results in the left panel suggest that the growth dividend from reducing income inequality by the average sample reduction are relatively small (up to about $0.05 \mathrm{pp}$ ). Unsurprisingly, this would be counterproductive for the countries with an initial level of net Gini below the identified overhang level, albeit to a very small extent. The right panel shows that a more ambitious reduction in income inequality would have more sizable effects on growth, ranging from about zero percent to about 0.43 percent. Even in this case, the negative effects on growth would be very small, while the largest benefits would accrue to Western Hemisphere countries plus Zimbabwe, China, and India.

\subsection{Financial Inclusion}

We now analyze how financial inclusion shapes the polynomial relationship between inequality and economic development. As a proxy for financial inclusion, we take the financial institutions access indicator by Svirydzenka (2016), which measures how accessible financial services are. ${ }^{23}$ By allowing for interaction terms between net Gini (and squared net Gini) and the financial access indicator, we first estimate the conditional coefficients and then plot the relationship for steady state values of financial access. ${ }^{24}$

Figure 6 shows the variations of the average relationship for different levels and changes of financial access. In the left panel, we show the familiar concave shape of the polynomial relationship. For average levels of financial access, the concave phase of the polynomial is similar to what we already observed. However, higher levels of financial access moves the negatively sloped portion of the relationship towards lower levels of net Gini and steepen it. On the contrary, lower levels of financial access flatten the concavity, pushing the negatively sloped portion of the relationship towards higher levels of net Gini. The middle panel presents the derivative for different changes in financial access. These results confirm that increases in income inequality in presence of a financial system characterized by more (less) inclusion have larger (smaller) negative returns on income, and that the overhang level of income inequality is lower (higher). The right panel depicts the relationship between changes in net Gini and real per capita GDP growth. Consistent with the other panels, the negative effects on growth from changes in income inequality are larger when financial access is easier.

Figure 7 presents in a three-dimensional chart what value the derivative of real per capita GDP takes for different levels of income inequality and financial access. Conveniently, we also plot the surface corresponding to the inequality overhang level, i.e. when the derivative switches from positive to negative. For average levels of financial access, the overhang level of net Gini is about 27 percent as in our results without interaction terms, and the derivative becomes more negative as income inequality increases. The chart also shows that financial inclusion matters. In particular, for high levels of financial access the negative steepness of the surface is more pronouncedespecially when income is highly concentrated - depicting a larger negative impact of income inequality on economic development and a lower inequality overhang level. For low levels of financial access, the derivative can still take negative values, and the overhang occurs at higher levels of in-

\footnotetext{
${ }^{22}$ See Appendix A for details regarding regional groups.

${ }^{23}$ The variable for financial access is constructed using the number of bank branches and ATMs per 100,000 adults.

${ }^{24}$ See Appendix B for the results of the mean group estimations.
} 
Figure 6: Variations of the Average Relationship for Different Levels and Changes of Financial Access
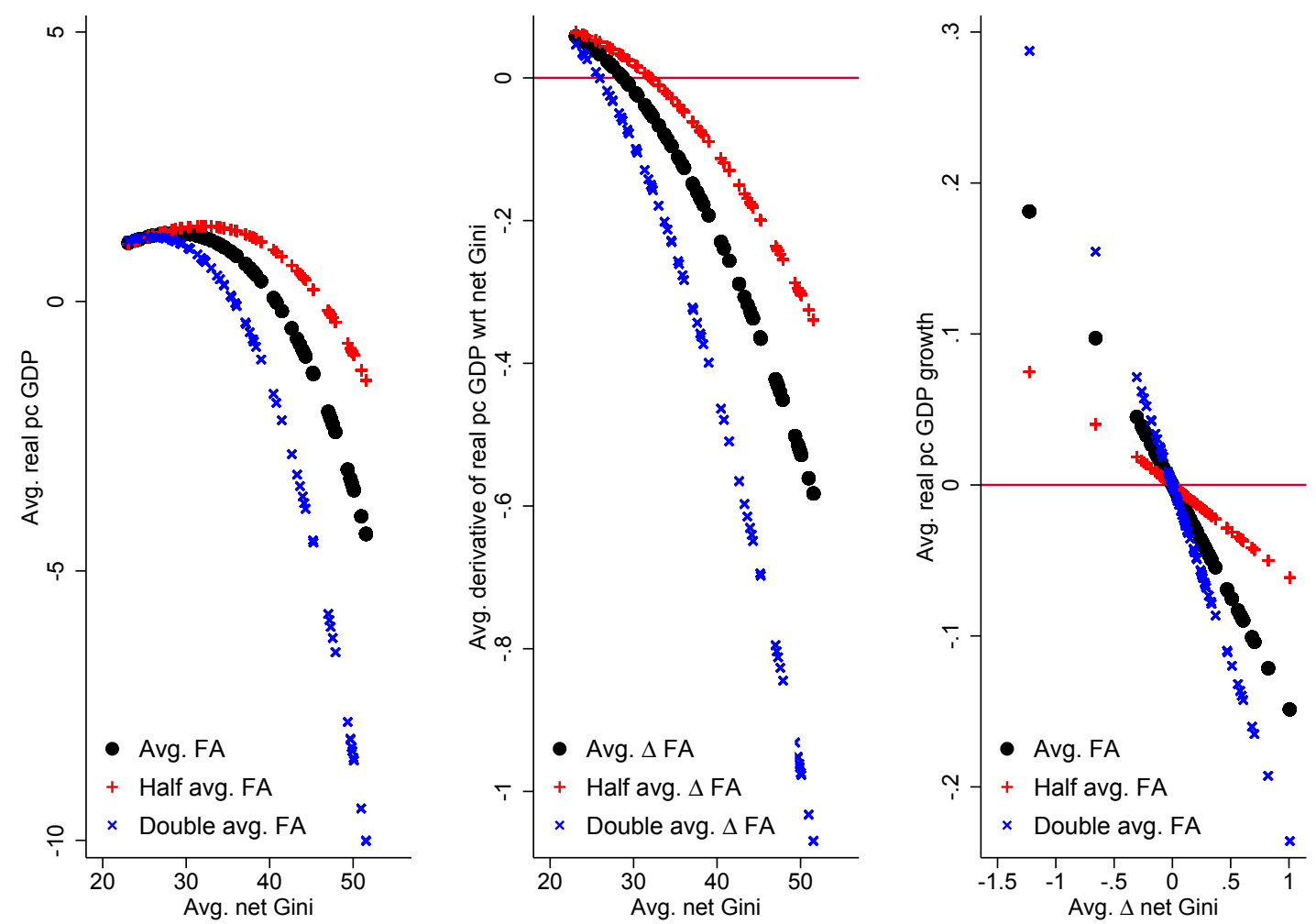

Source: Authors' calculations.

come inequality.

These results suggest that, in a context of high income concentration, widespread financial inclusion can exacerbate the negative effects of income inequality on economic development. These perhaps counter-intuitive findings are in line with the ones of Blaum (2012). In a somewhat different framework, he finds that the effect of income inequality on value added shares becomes larger when financial development improves. ${ }^{25}$ One possible explanation deals with the credit constraints of the poorer portion of the population. Specifically, in an environment characterized by a widespread access to financial services, the portion of credit-constrained borrowers without financial access is smaller than in the case characterized by limited financial access. To the extent that financial access is associated to a relaxation of the budget constraints, raising income inequality would lead banks to turn less prone to provide credit to those at the lower end of the income distribution that have access to services but that became relatively poorer and saw a deterioration in their ability to meet obligations.

\footnotetext{
${ }^{25}$ Blaum (2012) also find that for very high levels of financial development, the effect is reversed.
} 
Figure 7: Average Derivative for Varying Levels of Net Gini and Financial Access

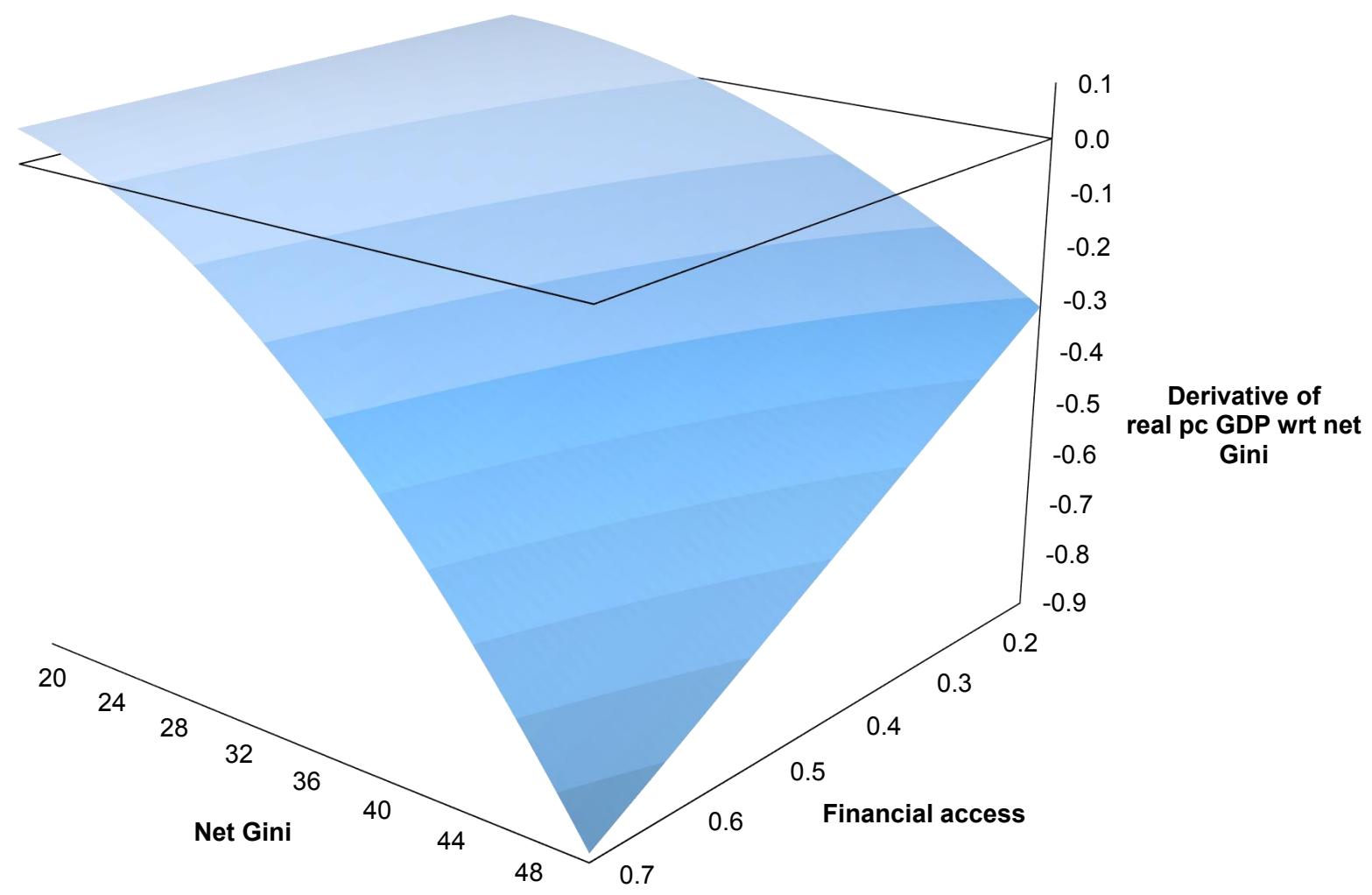

Source: Authors' calculations.

\subsection{Female Labor Participation}

We turn to analyze whether more female participation can soften the negative effects of income inequality on growth. As in the case of financial inclusion, we allow for interaction terms between net Gini (and squared net Gini) and female labor participation. In particular, relying on the crosssection regressions, we estimate the mean group coefficients and use them to plot the polynomial relationship for steady state levels of female labor participation. ${ }^{26}$

Figure 8 presents the variations of the average relationship for different levels and changes of female labor participation. The left panel displays the familiar concave average polynomial relationship, which suggests that for average levels of female labor participation, the relationship changes its slope from positive to negative when net Gini increases. As expected, and differently from the case of financial inclusion, when female labor participation is high enough, the polynomial takes a less negatively-sloped shape. However, when female labor participation is low, the negative slope of the relationship is more accentuated.

The other panels of Figure 8 allow to dig deeper into the variations of the polynomial relationship. The middle panel shows that for any size of the change in female labor participation, the overhang occurs at about the same level of net Gini obtained from the conditional specification without in-

\footnotetext{
${ }^{26}$ See Appendix B for the results of the mean group estimations.
} 
teraction terms. Consistent with the left panel, for large (small) enough increases in female labor participation, the negative effect of income inequality on economic development is less (more) negative. The right panel shows the impact of changes in net Gini on real per capita GDP growth at different levels of female labor participation. The results confirm that female labor participation can act as an absorber for positive shocks of net Gini on growth, by reducing its negative impact.

Figure 8: Variations of the Average Relationship for Different Levels and Changes of Female Labor Participation
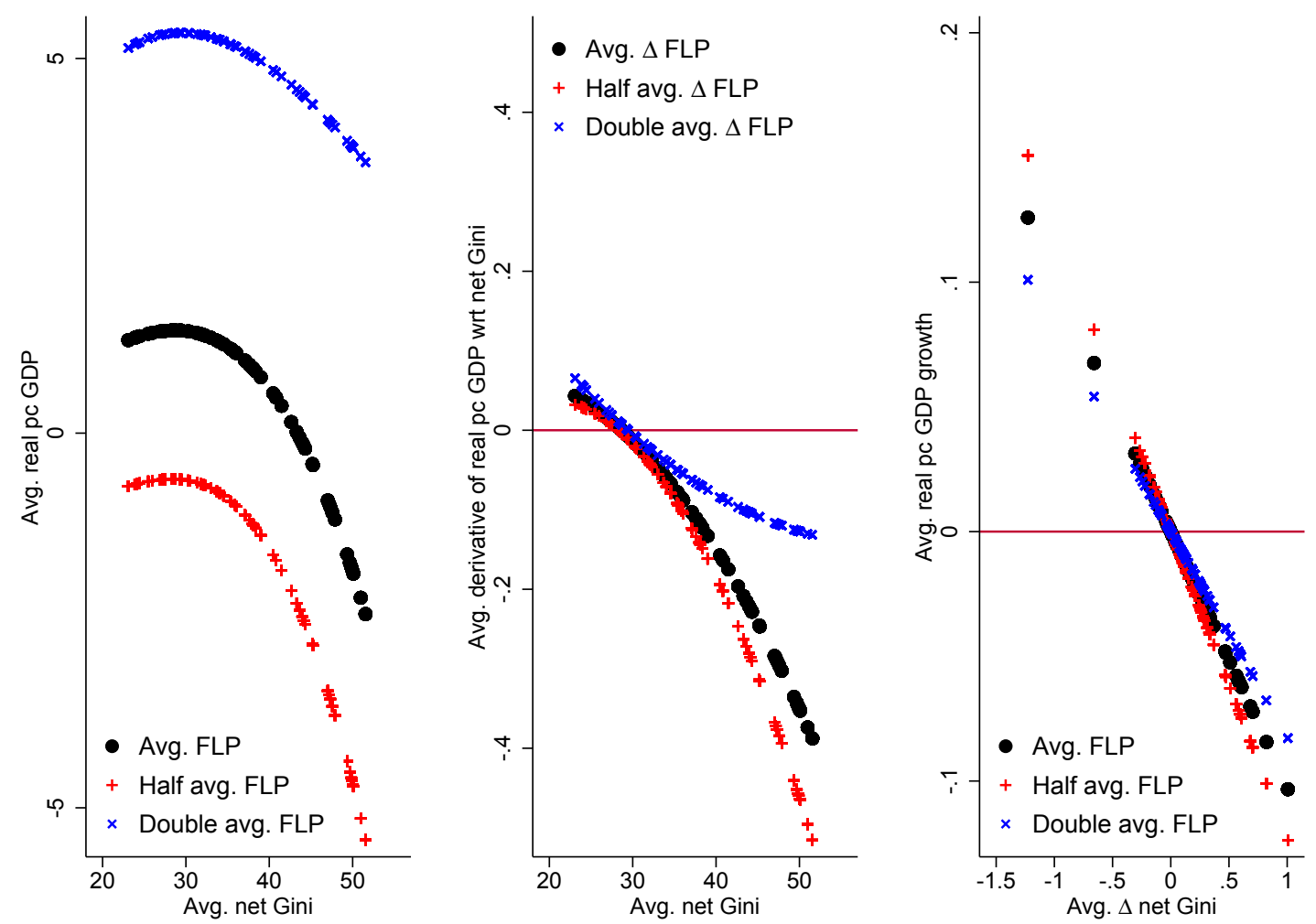

Source: Authors' calculations.

As for financial access, we plot in three dimensions the average derivative as a function of net Gini and female labor participation in Figure 9, along with the surface corresponding to the inequality overhang. The chart suggests that female labor participation plays a key role in shaping the relationship. Specifically, increases in income inequality have larger negative effects on economic development when female labor participation is low. Consistently, when income is less concentrated, the positive effects of raising income inequality on economic development are larger when female labor participation is high. In essence, high levels of female participation can reduce the negative effects of income inequality on economic development and strengthen the positive effects.

\subsection{Robustness}

To check robustness of the results we added other controls to the specification. In particular, labor productivity and government spending turn out insignificant and do not alter the main conclusions. Years of schooling or the completion rate for primary and secondary education, as well as 
Figure 9: Average Derivative for Varying Levels of Net Gini and Female Labor Participation

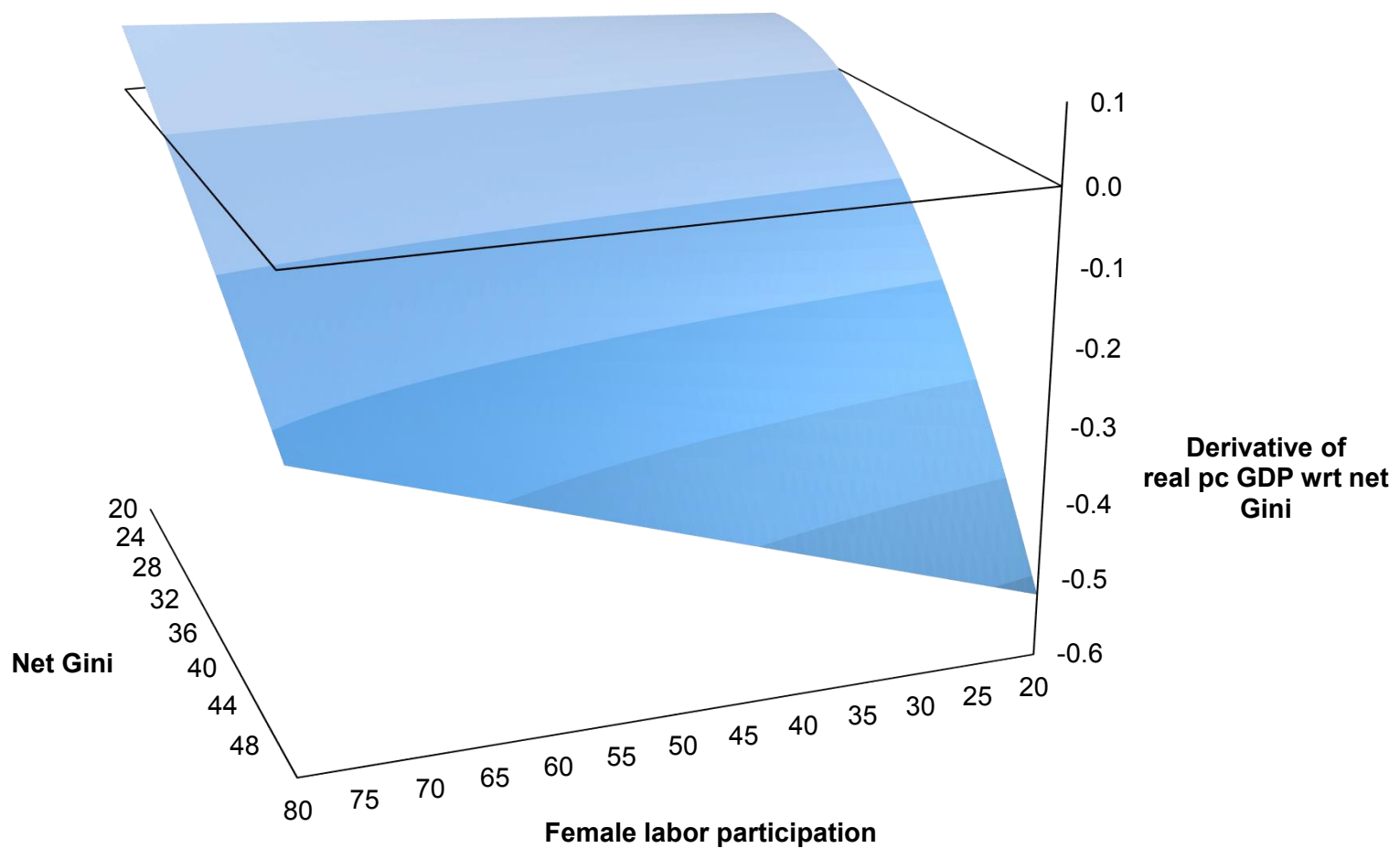

Source: Authors' calculations.

education expenditure, either greatly reduce the number of cross-section regressions or turn out insignificant. Further, they introduce selection bias as mainly AE have annual data over the period 1990-2010. Notwithstanding data limitations, the shape of the average conditional relationship is similar to the one presented.

With respect to the interaction terms, we run some robustness tests. We substitute the financial access index with ATMs per 100,000 adults and commercial bank branches per 100,000 adults. While the steepness of the relationship varies, the main results hold. Namely, an increase in the variable proxying financial access is associated with a more negative impact of income inequality on economic development. For female labor participation, we replace the indicator from the International Labour Organization with that from the World Development Indicators of the World Bank. Despite the drastic reduction in observations, the conclusions of our analysis prove robust.

We also repeated the entire analysis using market Gini instead of net Gini. This is not rigorously a robustness test as pre-redistribution data neglect the effects of various policy interventions, however it can still provide insights about the strength of the relationship. The results are broadly consistent with the ones presented. Consistent with higher values of market Gini with respect to net Gini, the inequality overhang occurs at a market Gini of 34 percent. 


\section{Conclusions}

The theoretical literature analyzing the impact of income inequality on economic development recognizes the possibility of nonlinear effects. However, only a few empirical studies looked into nonlinearities, and generally only by allowing for heterogeneous effects across countries or subsets of countries, or by including a quadratic term of the income inequality measure in the equation to be estimated. This paper explores nonlinearities in the relationship between income inequality and economic development with an empirical framework that is robust to endogeneity caused by different issues. Within such nonlinear framework, it also analyzes the existence of possible trade-offs associated with two policies often considered when aiming to spurring growth, namely boosting financial inclusion and promoting female labor participation.

We find pervasive evidence of nonlinearities, as the relationship between income inequality and economic development for the observed levels of income inequality is, on average, concave. Also, our findings suggest that the slope of the polynomial relationship from positive turns negative at a net Gini of about 27 percent, indicating that the inequality overhang occurs at low levels of income inequality. Finally, we find that in an environment characterized by widespread financial access and high income concentration, rising income inequality has a larger negative impact on economic development because banks may curtail credit to customers at the lower end of the income distribution, who became poorer and suffered a deterioration in their ability to repay. Female labor participation, on the other hand, can effectively contribute to reduce such negative impact and strengthening the positive one (typical of countries experiencing low levels of income inequality), by enlarging the pool of talents that are available to work.

Our results bear some policy implications. On the one hand, they highlight the need to consider possible trade-offs at the time in which financial access improves. While financial inclusion is generally desirable, it can lead to a more negative effect of income inequality on economic development under certain circumstances. Thus, mechanisms to ensure that those that loose access to credit can continue smoothing their consumption should be considered to help reducing such negative effect. On the other hand, our results are supportive of policies aimed at increasing female labor participation. Contrary to financial inclusion, we do not find evidence of negative side effects from boosting the participation of women to economic activity. 


\section{References}

Al Masri, Diala and Peter Pedroni (2016). "Nonlinearities in Financial Development; The Good, the Bad, and the Beautiful". In: Williams College Working Paper.

Alesina, Alberto and Roberto Perotti (1996). "Income Distribution, Political Instability, and Investment". In: European Economic Review 40.6, pp. 1203-1228.

Alesina, Alberto and Dani Rodrik (1991). Distributive Politics and Economic Growth. Tech. rep. National Bureau of Economic Research.

Arcand, Jean Louis, Enrico Berkes, and Ugo Panizza (2015). "Too much finance?" In: Journal of Economic Growth 20.2, pp. 105-148.

Atkinson, Anthony B, Thomas Piketty, and Emmanuel Saez (2011). "Top Incomes in the Long Run of History". In: Journal of Economic Literature 49.1, pp. 3-71.

Banerjee, Abhijit V and Esther Duflo (2003). "Inequality and Growth: What Can the Data Say?" In: Journal of Economic Growth 8.3, pp. 267-299.

Barro, Robert J (2000). "Inequality and Growth in a Panel of Countries". In: Journal of Economic Growth 5.1, pp. 5-32.

Benabou, Roland (1996). "Inequality and Growth". In: NBER Macroeconomics Annual 1996, Volume 11. MIT Press, pp. 11-92.

Benhabib, Jess (2003). "The Tradeoff between Inequality and Growth". In: Annals of Economics and Finance 4, pp. 491-507.

Bjørnskov, Christian (2008). "The Growth-Inequality Association: Government Ideology Matters". In: Journal of Development Economics 87.2, pp. 300-308.

Blaum, Joaquin et al. (2012). "Wealth Inequality and the Losses from Financial Frictions". In: 2012 Meeting Papers. 1077. Society for Economic Dynamics.

Cavaliere, Giuseppe (2005). "Limited Time Series with a Unit Root". In: Econometric Theory 21.05, pp. 907-945.

Cecchetti, Stephen G and Enisse Kharroubi (2012). "Reassessing the Impact of Finance on Growth". In: BIS working paper No. 381.

Chen, Been-Lon (2003). "An Inverted-U Relationship Between Inequality and Long-Run Growth". In: Economics Letters 78.2, pp. 205-212.

Cho, Dooyeon, Bo Min Kim, and Dong-Eun Rhee (2014). "Inequality and Growth: Nonlinear Evidence from Heterogeneous Panel Data". In: KIEP Research Paper No. Working Papers-14-01.

Dabla-Norris, E, Yan Ji, Robert Townsend, and DF Unsal (2015a). "Identifying Constraints to Financial Inclusion and Their Impact on GDP and Inequality: A Structural Framework for Policy". In: International Monetary Fund Working Paper 15/22.

Dabla-Norris, Era, Kalpana Kochhar, Nujin Suphaphiphat, Frantisek Ricka, and Evridiki Tsounta (2015b). "Causes and Consequences of Income Inequality: a Global Perspective". In: International Monetary Fund SDN/15/13.

De Dominicis, Laura, Henri LF De Groot, and Raymond JGM Florax (2006). "Growth and Inequality: a Meta-Analysis". In: Tinbergen Institute Discussion Paper 064/3.

Duflo, Esther (2012). "Women Empowerment and Economic Development". In: Journal of Economic Literature 50.4, pp. 1051-1079.

Fallah, Belal N and Mark Partridge (2007). "The Elusive Inequality-Economic Growth Relationship: Are There Differences between Cities and the Countryside?" In: The Annals of Regional Science 41.2, pp. 375-400.

Galor, Oded (2000). "Income Distribution and the Process of Development". In: European Economic Review 44.4, pp. 706-712.

Galor, Oded and Omer Moav (2004). "From Physical to Human Capital Accumulation: Inequality and the Process of Development". In: The Review of Economic Studies 71.4, pp. 1001-1026. 
Gonzales, Christian, Sonali Jain-Chandra, Kalpana Kochhar, Monique Newiak, Tlek Zeinullayev, et al. (2015). "Catalyst for Change: Empowering Women and Tackling Income Inequality". In: International Monetary Fund SDN/15/20.

Granger, Clive WJ (2010). "Some Thoughts on the Development of Cointegration". In: Journal of Econometrics 158.1, pp. 3-6.

Greenwood, Jeremy and Boyan Jovanovic (1990). "Financial Development, Growth, and the Distribution of Income". In: Journal of Political Economy 98.5, Part 1, pp. 1076-1107.

Grigoli, Francesco, Evelio Paredes, and Gabriel Di Bella (2016). "Inequality and Growth: A Heterogeneous Approach". In: International Monetary Fund Working Paper 16/244.

Im, Kyung So, M Hashem Pesaran, and Yongcheol Shin (2003). "Testing for Unit Roots in Heterogeneous Panels". In: Journal of Econometrics 115.1, pp. 53-74.

Iversen, Torben and John D Stephens (2008). "Partisan Politics, the Welfare State, and Three Worlds of Human Capital Formation". In: Comparative Political Studies 41.4-5, pp. 600-637.

Jenkins, Stephen P (2015). "World Income Inequality Databases: an Assessment of WIID and SWIID". In: The Journal of Economic Inequality 13.4, pp. 629-671.

Kao, Chihwa (1999). "Spurious Regression and Residual-Based Tests for Cointegration in Panel Data". In: Journal of Econometrics 90.1, pp. 1-44.

Kim, Byung-Yeon and Jukka Pirttila (2003). "The Political Economy of Reforms: Empirical Evidence from Post-Communist Transition in the 1990s". In:

Kolev, Galina and Judith Niehues (2016). "The Inequality-Growth Relationship-An Empirical Reassessment". In: IW-Report 7/2016.

Kraay, Aart (2015). "Weak Instruments in Growth Regressions: Implications for Recent CrossCountry Evidence on Inequality and Growth". In: World Bank Policy Research Working Paper 7494.

Krugman, Paul (1988). "Financing vs. Forgiving A Debt Overhang". In: Journal of Development Economics 29.3, pp. 253-268.

Kuznets, Simon (1955). "Economic Growth and Income Inequality". In: American Economic Review 45.1, pp. 1-28.

Levin, Andrew, Chien-Fu Lin, and Chia-Shang James Chu (2002). "Unit Root Tests in Panel Data: Asymptotic and Finite-Sample Properties". In: Journal of Econometrics 108.1, pp. 124.

Levine, Ross (1997). "Financial Development and Economic Growth: Views and Agenda". In: Journal of Economic Literature 35.2, pp. 688-726.

Lin, Shu-Chin, Ho-Chuan Huang, Dong-Hyeon Kim, and Chih-Chuan Yeh (2009). "Nonlinearity between Inequality and Growth". In: Studies in Nonlinear Dynamics \& Econometrics 13.2.

Maddala, Gangadharrao S and Shaowen Wu (1999). "A Comparative Study of Unit Root Tests with Panel Data and a New Simple Test". In: Oxford Bulletin of Economics and Statistics 61.S1, pp. 631-652.

Masten, Arjana Brezigar, Fabrizio Coricelli, and Igor Masten (2008). "Non-linear Growth Effects of Financial Development: Does Financial Integration Matter?" In: Journal of International Money and Finance 27.2, pp. 295-313.

Miller, Grant (2008). "Women's Suffrage, Political Responsiveness, and Child Survival in American History". In: The Quarterly Journal of Economics 123.3, p. 1287.

Morgan, Jana and Nathan J Kelly (2013). "Market Inequality and Redistribution in Latin America and the Caribbean". In: The Journal of Politics 75.03, pp. 672-685.

Ostry, Jonathan David and Andrew Berg (2011). "Inequality and Unsustainable Growth: Two Sides of the Same Coin?" In: International Monetary Fund SDN/11/08.

Ostry, Jonathan David, Andrew Berg, and Charalambos G Tsangarides (2014). "Redistribution, Inequality, and Growth". In: International Monetary Fund SDN/14/02.

Pagano, Marco (1993). "Financial Markets and Growth: An Overview". In: European Economic Review 37.2-3, pp. 613-622. 
Pedroni, Peter (1999). "Critical Values for Cointegration Tests in Heterogeneous Panels with Multiple Regressors". In: Oxford Bulletin of Economics and statistics 61.s 1, pp. 653-670.

- (2004). "Panel Cointegration: Asymptotic and Finite Sample Properties of Pooled Time Series Tests with an Application to the PPP Hypothesis". In: Econometric Theory 20.03, pp. 597625.

- (2007). "Social Capital, Barriers to Production and Capital Shares: Implications for the Importance of Parameter Heterogeneity from a Nonstationary Panel Approach". In: Journal of Applied Econometrics 22.2, pp. 429-451.

Piketty, Thomas and Emmanuel Saez (2003). "Income Inequality in the United States, 1913-1998". In: The Quarterly Journal of Economics 118.1, pp. 1-41.

Rajan, Raghuram G (2011). Fault Lines: How Hidden Fractures Still Threaten the World Economy. Princeton University Press.

Sahay, Ratna, Martin Čihák, Papa N’Diaye, and Adolfo Barajas (2015). "Rethinking Financial Deepening: Stability and Growth in Emerging Markets". In: International Monetary Fund $\mathrm{SDN} / 15 / 08$.

Solt, Frederick (2016). "The Standardized World Income Inequality Database". In: Social Science Quarterly 97.

Svirydzenka, Katsiaryna (2016). "Introducing a New Broad-based Index of Financial Development". In: International Monetary Fund Working Paper 16/5.

Teignier, Marc and David Cuberes (2014). "Aggregate Costs of Gender Gaps in the Labor Market: A Quantitative Estimate". In: UB Economics Working Papers 2014/308.

Thomas, Duncan (1990). "Intra-Household Resource Allocation: An Inferential Approach". In: Journal of Human Resources, pp. 635-664. 


\section{Appendix A. Data Sources and Country Groups}

Table A.1 lists all variables used in the paper, along with the source and the scale.

Table A.1: Data Sources

\begin{tabular}{lll} 
Variable & Source & Scale \\
\hline ATMs per 100,000 adults & Financial Access Survey & Units \\
Commercial branches per 100,000 adults & Financial Access Survey & Units \\
Completion rate primary education & World Development Indicators & Percent \\
Completion rate secondary education & World Development Indicators & Percent \\
Female labor participation & International Labour Organization & Percent \\
& World Development Indicators & Percent \\
Financial access & Svirydzenka (2016) & Index \\
Government expenditure & World Economic Outlook & Percent of GDP \\
Education expenditure & IMF's Fiscal Affairs Department database & Percent of GDP \\
Investment & World Economic Outlook & Percent of GDP \\
Labor productivity & World Economic Outlook & Index \\
Market Gini & SWIID 5.1 & Index \\
Net Gini & SWIID 5.1 & Index \\
Population growth & World Economic Outlook & Percent \\
Real per capita GDP & Penn World Tables 9.0 & PPP \\
Terms of trade & World Economic Outlook & Index \\
Trade openness & World Economic Outlook & Percent \\
Years of schooling & Barro-Lee Database & Units \\
\hline
\end{tabular}

We create regional groups according to the IMF regional departments. Specifically, the regional groups include the following countries:

Africa: Botswana, Ghana, Malawi, Mali, Nigeria, Rwanda, Sierra Leone, South Africa, Uganda, Zambia, Zimbabwe.

Asia and Pacific: Australia, Bangladesh, China, India, Indonesia, Japan, Malaysia, New Zealand, Philippines, Singapore, Sri Lanka, Taiwan.

Europe: Austria, Belarus, Belgium, Bulgaria, Croatia, Cyprus, Czech Rep., Finland, France, Germany, Greece, Hungary, Iceland, Ireland, Israel, Italy, Latvia, Lithuania, Luxembourg, Norway, Poland, Portugal, Russian Federation, Slovakia, Sweden, Switzerland, Turkey, Ukraine, United Kingdom.

Middle East and Central Asia: Armenia, Egypt, Jordan, Kazakhstan, Mauritania, Morocco, Pakistan, Tajikistan, Tunisia.

Western Hemisphere: Argentina, Brazil, Canada, Chile, Colombia, Costa Rica, Dominican Rep., Ecuador, El Salvador, Guatemala, Honduras, Mexico, Panama, Paraguay, Peru, United States.

And the income levels include the following countries:

Advanced Economies: Australia, Austria, Belgium, Canada, Cyprus, Czech Rep., Finland, France, Germany, Greece, Iceland, Ireland, Israel, Italy, Japan, Latvia, Lithuania, Luxembourg, New Zealand, Norway, Portugal, Singapore, Slovakia, Sweden, Switzerland, Taiwan, United Kingdom, United States.

Emerging Markets: Argentina, Armenia, Belarus, Botswana, Brazil, Bulgaria, Chile, China, 
Colombia, Costa Rica, Croatia, Dominican Republic, Ecuador, Egypt, El Salvador, Guatemala, Hungary, India, Indonesia, Jordan, Kazakhstan, Malaysia, Mexico, Morocco, Pakistan, Panama, Paraguay, Peru, Philippines, Poland, Russian Federation, South Africa, Sri Lanka, Tunisia, Turkey, Ukraine.

Low Income Developing Countries: Bangladesh, Ghana, Honduras, Malawi, Mali, Mauritania, Nigeria, Rwanda, Sierra Leone, Tajikistan, Uganda, Zambia, Zimbabwe. 


\section{Appendix B. Regression Results}

Table B.1 presents the results of the mean group estimations.

Table B.1: Mean Group Estimations

\begin{tabular}{|c|c|c|c|c|c|c|c|c|}
\hline & \multirow{2}{*}{$\begin{array}{c}\begin{array}{c}\text { Unconditional } \\
\text { regression }\end{array} \\
(1)\end{array}$} & \multicolumn{5}{|c|}{ Conditional regressions } & \multirow{2}{*}{$\begin{array}{l}\text { Conditional } \\
\text { regression with } \\
\text { inter. terms } \\
\text { between FA } \\
\text { and net Gini } \\
(7)\end{array}$} & \multirow{2}{*}{$\begin{array}{l}\text { Conditional } \\
\text { regression with } \\
\text { inter. terms } \\
\text { between FLP } \\
\text { and net Gini } \\
\text { (8) }\end{array}$} \\
\hline & & (2) & (3) & (4) & (5) & (6) & & \\
\hline Net Gini & $\begin{array}{l}0.0024^{*} \\
(1.646)\end{array}$ & $\begin{array}{l}0.0048 \\
(1.218)\end{array}$ & $\begin{array}{l}0.0050 \\
(1.142)\end{array}$ & $\begin{array}{l}0.0021 \\
(0.379)\end{array}$ & $\begin{array}{l}0.0035^{*} \\
(1.678)\end{array}$ & $\begin{array}{l}0.0031^{*} \\
(1.701)\end{array}$ & $\begin{array}{c}0.0039^{* * *} \\
(3.441)\end{array}$ & $\begin{array}{c}0.0182^{* * *} \\
(6.070)\end{array}$ \\
\hline Net Gini squared & $\begin{array}{l}-0.0001^{* *} \\
(-2.504)\end{array}$ & $\begin{array}{c}-0.0001^{* * *} \\
(-2.917)\end{array}$ & $\begin{array}{c}-0.0001^{* * *} \\
(-2.734)\end{array}$ & $\begin{array}{l}-0.0001^{*} \\
(-1.827)\end{array}$ & $\begin{array}{c}-0.0001^{* *} \\
(-2.066)\end{array}$ & $\begin{array}{l}-0.0001^{*} \\
(-1.957)\end{array}$ & $\begin{array}{c}-0.0001^{* * *} \\
(-4.391)\end{array}$ & $\begin{array}{c}-0.0003^{* * *} \\
(-7.341)\end{array}$ \\
\hline Initial (log) real per capita GDP & & $\begin{array}{c}0.0087^{\star *} \\
(2.452)\end{array}$ & $\begin{array}{l}0.0028 \\
(0.788)\end{array}$ & $\begin{array}{l}0.0052 \\
(1.477)\end{array}$ & $\begin{array}{l}0.0057 \\
(1.596)\end{array}$ & $\begin{array}{c}0.0085^{* *} \\
(2.199)\end{array}$ & $\begin{array}{c}0.0246^{* * *} \\
(20.733)\end{array}$ & $\begin{array}{c}0.0108^{* \star *} \\
(14.510)\end{array}$ \\
\hline Trade openness & & & $\begin{array}{c}0.0005^{* * *} \\
(9.235)\end{array}$ & $\begin{array}{c}0.0005^{* * *} \\
(9.277)\end{array}$ & $\begin{array}{c}0.0005^{* * *} \\
(8.275)\end{array}$ & $\begin{array}{c}0.0004^{* \star *} \\
(7.637)\end{array}$ & $\begin{array}{c}0.0004^{* * *} \\
(3.668)\end{array}$ & $\begin{array}{c}0.0005^{* \star *} \\
(4.665)\end{array}$ \\
\hline Terms of trade & & & & $\begin{array}{l}0.0003 \\
(0.839)\end{array}$ & $\begin{array}{l}0.0003 \\
(0.751)\end{array}$ & $\begin{array}{l}0.0002 \\
(0.416)\end{array}$ & $\begin{array}{l}0.0000 \\
(0.017)\end{array}$ & $\begin{array}{l}-0.0000 \\
(-0.107)\end{array}$ \\
\hline Investment in percent of GDP & & & & & $\begin{array}{c}0.0019^{* * *} \\
(3.593)\end{array}$ & $\begin{array}{c}0.0018^{* * *} \\
(3.177)\end{array}$ & $\begin{array}{l}0.0012^{\star * *} \\
(12.115)\end{array}$ & $\begin{array}{l}0.0013^{* * *} \\
(12.816)\end{array}$ \\
\hline Population growth & & & & & & $\begin{array}{c}0.0073^{* * *} \\
(2.826)\end{array}$ & $\begin{array}{l}0.0081^{* * *} \\
(15.549)\end{array}$ & $\begin{array}{c}0.0093^{* * *} \\
(18.297)\end{array}$ \\
\hline Financial access & & & & & & & $\begin{array}{c}-0.1292^{* * *} \\
(-2.791)\end{array}$ & \\
\hline Financial access * net Gini & & & & & & & $\begin{array}{c}0.0132^{* * *} \\
(5.246)\end{array}$ & \\
\hline Financial access * net Gini squared & & & & & & & $\begin{array}{c}-0.0003^{* * *} \\
(-9.835)\end{array}$ & \\
\hline Female labor participation & & & & & & & & $\begin{array}{c}0.0081^{* * *} \\
(7.199)\end{array}$ \\
\hline Female labor participation * net Gini & & & & & & & & $\begin{array}{c}-0.0003^{* * *} \\
(-5.027)\end{array}$ \\
\hline Female labor participation * net Gini squared & & & & & & & & $\begin{array}{c}0.0000^{* * *} \\
(4.854)\end{array}$ \\
\hline Constant & $\begin{array}{l}0.0777^{*} \\
(1.664)\end{array}$ & $\begin{array}{l}-0.0578 \\
(-0.476)\end{array}$ & $\begin{array}{l}-0.0545 \\
(-0.350)\end{array}$ & $\begin{array}{l}-0.0612 \\
(-0.586)\end{array}$ & $\begin{array}{l}-0.1364 \\
(-1.366)\end{array}$ & $\begin{array}{l}-0.1407 \\
(-1.328)\end{array}$ & $\begin{array}{c}-0.3012^{\star * *} \\
(-10.711)\end{array}$ & $\begin{array}{c}-0.5698^{* * *} \\
(-9.320)\end{array}$ \\
\hline Observations & 1449 & 1449 & 1412 & 1397 & 1397 & 1395 & 1352 & 1352 \\
\hline
\end{tabular}

Source: Authors' calculations.

Notes: ${ }^{* *},{ }^{* *}$, and ${ }^{*}$ next to a number indicate statistical significance at 1,5 , and 10 percent, respectively. 